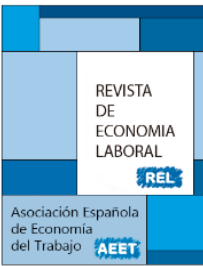

\title{
¿ES SOSTENIBLE EL ACTUAL MODELO LABORAL?
}

\section{Resumen}

\author{
Juan Ignacio Palacio Morena** y Jorge Aragón Medina* \\ ${ }^{*} \mathrm{CCOO} * *$ Universidad Castilla La Mancha
}

Recibido Julio 2015; Aceptado Octubre 2015

El artículo analiza si el actual modelo laboral es capaz de generar empleo suficiente y de la calidad necesaria para que las cotizaciones sociales puedan financiar las prestaciones contributivas del sistema de protección social. Parte de considerar que el modelo productivo y de crecimiento de la economía española ha mantenido altas tasas de desempleo y bajos niveles de calidad del empleo y productividad, y que las reformas laborales llevadas a cabo y especialmente la adoptada en 2012, se han dirigido a reducir los costes laborales en vez de fomentar el aumento de la productividad generando una continua espiral devaluadora. Se analizan los ciclos de creación y destrucción de empleo, vinculados a la evolución del crecimiento económico y la productividad, que son los principales condicionantes de los ingresos por cotizaciones, comparándolos con la evolución de los gastos en prestaciones contributivas a través de la información de las fuentes tributarias y de la Seguridad Social. De su análisis concluye que las características y tendencias del mercado de trabajo apuntan a un creciente desequilibrio entre cotizaciones y prestaciones contributivas que hacen insostenible el actual sistema de protección social.

Palabras clave: Mercado de trabajo, empleo, salarios, costes laborales, productividad, cotizaciones sociales, prestaciones sociales, sistema de protección social, Estado de bienestar Clasificación JEL: J21; J31; J65; H55

\section{Abstract}

This paper analyzes the question of whether the labor model in Spain is able to create enough employment of quality to guarantee that the social contributions can finance the contributory benefits of the social protection system. It shows that the productive and growth model of the Spanish economy is characterized by high levels of unemployment, low quality of employment and low productivity, and that the labor reforms adopted-especially in 2012- had the objective of reducing the labor costs instead of increasing productivity, generating a continuous devaluation spiral that reinforces the characteristics described. The article studies the cycles of creation and destruction of employment in relation with economic growth and productivity, as the main variables that affect the income from social contributions, and compares them with the expenditures of the contributory benefits of the social protection system, using information from the tax and social security statistics. It concludes that the tendencies of the labor market show an increasing imbalance between social contributions and social benefits that will make the social protection system unsustainable.

Key words: Labor market, employment, wages, labor costs , productivity, social contributions, social benefits, social welfare system, welfare state

JEL Classification: J21; J31; J65; H55

(C) Revista de Economía Laboral 


\section{Introducción}

Más allá de las consecuencias familiares y personales que la actual crisis ha tenido en España, con una tasa de paro muy elevada y una caída significativa de los salarios, se plantea si una estructura del mercado de trabajo con esas características permite generar suficientes recursos (cotizaciones) para sostener los gastos en las prestaciones de carácter contributivo. La tasa de paro en España se ha mantenido persitentemente por encima de la media europea y con frecuencia ha duplicado dicha media. Ese desajuste en el mercado de trabajo se ha tratado de corregir unilateralmente por la vía de la paulatina reducción de los costes laborales, relegando a un segundo plano la mejora de la productividad.

En realidad esto es la consecuencia de un modelo de crecimiento económico que se ha basado, tradicionalmente, en la importación de tecnología como vía de mejora de la productividad, sin que paralelamente se haya hecho un esfuerzo de innovación propia. En consecuencia, los incrementos de productividad han sido muy desiguales entre sectores y empresas, y han tenido un carácter anticíclico. La productividad ha crecido sobre todo en las recesiones como efecto de la destrucción de empleo. En las etapas de auge la productividad apenas ha variado y cuando lo ha hecho, como ocurrió en la década de 1960, ha sido porque el nivel de partida era ínfimo. De ahí también que en las expansiones el déficit comercial tienda a aumentar y a frenarse cuando el crecimiento pierde fuerza. Los desajustes que han ido surgiendo entre las variaciones de la productividad y de los costes laborales se han saldado con sucesivas reducciones de estos últimos para tratar de corregirlos.

De nuevo, las reformas que se implantan para tratar de salir de la crisis vuelven a incidir en actuar, fundamentalmente, sobre el mercado de trabajo para reducir costes laborales, en vez de priorizar los cambios en los mercados de bienes y servicios para introducir mayor competencia e incentivar la mejora de la productividad (Toharia, 2011; Conde Ruiz, Felgueroso y García Pérez, 2010; Aragón, Cruces, Durán y Rocha, 2005). No se trata, sin embargo, de una reforma más que da continuidad a las anteriores. Hasta la reforma que se inicia en 2012 no se habían desarticulado los cauces e instrumentos que permitían recomponer los ajustes entre el crecimiento de la productividad y el de los salarios. El principal hecho diferencial de la reforma todavía en curso es el intento de desactivar la negociación colectiva priorizando los convenios de empresa, la mucha mayor flexibilidad para la contratación y el despido, y la más amplia libertad para que el empresario modifique unilateralmente las 
condiciones de trabajo. La consecuencia es que la recuperación del empleo tiene un carácter tan precario que pone en cuestión la posibilidad de financiar las prestaciones sociales de carácter contributivo con las cotizaciones que se derivan de dicho crecimiento del empleo.

Se han utilizado diferentes vías para recortar costes laborales en las sucesivas reformas: fomento de los contratos temporales, reducción de costes de despido, rebaja de las prestaciones por desempleo, facilidades para la contratación a tiempo parcial y flexibilización en la fijación de las condiciones de trabajo. Al no modificarse sustancialmente el modelo de crecimiento introduciendo competencia en todos los mercados, incluidos los de ámbito más restringido (autonómico y local), la innovación propia y la consecuente mejora de la productividad se han visto muy limitadas ${ }^{1}$. Para compensar la baja productividad se ha buscado reducir costes laborales. Como hacerlo de forma directa sobre los salarios provoca un rechazo social más fuerte, se ha acudido a medios indirectos asociados a los tipos de contratación y a distintas vías de flexibilización de las condiciones de trabajo. Los contratos temporales y a tiempo parcial suponen salarios-hora inferiores; y los cambios en la definición de tareas y categorías han tendido a devaluar de hecho las remuneraciones. Con ello se ha conseguido también que las indemnizaciones por despido vayan reduciéndose, tanto porque se ha recortado la indemnización legal correspondiente como porque el progresivo acortamiento de la duración de los contratos limita la indemnización.

Se crea, por tanto, un círculo vicioso en vez de virtuoso. La inclinación a rebajar salarios y demás costes laborales, como forma de ajuste pasivo a la productividad, contribuye a que ésta última crezca menos. Los trabajadores acaban por tener menos incentivos $\mathrm{y}$ posibilidades para mejorar su rendimiento. Al frenarse o estancarse la productividad los salarios tienen necesariamente que terminar por adaptarse a la variación de la productividad. La espiral devaluadora se vuelve imparable. Menor productividad provoca que tarde o temprano haya que ajustar nuevamente los costes laborales. A su vez, el deterioro de los salarios y condiciones de trabajo contribuye a desincentivar el

\footnotetext{
${ }^{1}$ El concepto vigente de competencia, que la concibe como la maximización de beneficios a corto plazo mediante ajustes de precios, dificulta comprender que la verdadera competencia es la que busca maximizar beneficios a largo plazo mediante la innovación. Ese concepto distorsiona el sentido del emprendimiento y la innovación, que se interpretan como si se tratase de acciones esporádicas de carácter extraordinario y se pudiesen fomentar mediante las subvenciones y la desregulación, en vez de entender que precisamente lo que se necesita es una adecuada regulación de los mercados que estimule la innovación y la mejora de las condiciones y organización del trabajo. Para profundizar en esta cuestión véanse los trabajos de Palacio (2011) y Palacio y Álvarez (2004).
} 
rendimiento y la calidad del trabajo, lo que termina por contraer la productividad.

Con la crisis la productividad ha aumentado de forma significativa a corto plazo debido a la intensa y rápida destrucción de empleo. Sin embargo, el incremento de los salarios ha sido muy inferior al de la productividad. En la medida que ha habido una ligera recuperación, la productividad ha vuelto a frenarse, pero aún hay margen para una moderada mejora salarial. Incluso contando con esa tenue recuperación salarial y la continuidad en la creación de empleo, es difícil que las cotizaciones sociales que se recauden puedan alcanzar un adecuado equilibrio con la cuantía de las pensiones y demás prestaciones sociales de carácter contributivo. En un régimen de reparto, como el español, aunque se cuente con un importante fondo de reserva, el número de ocupados con los niveles de remuneraciones actuales y previsibles difícilmente pueden generar un volumen de cotizaciones sociales capaz de cubrir las prestaciones sociales de carácter contributivo.

Una forma de aproximarse a los cambios que en tal sentido ha supuesto la crisis es examinar la evolución en las remuneraciones salariales y las correspondientes cotizaciones, así como la de las pensiones y demás prestaciones de carácter contributivo. Hay distintas fuentes que dan datos al respecto, pero no son homogéneas entre sí. Eso dificulta la imprescindible combinación de las mismas para conseguir valorar la situación en los inicios de la crisis y en la actualidad. Un primer acercamiento es ver, a partir de las fuentes tributarias, qué ha sucedido con los salarios y las pensiones ${ }^{2}$. Dado los cambios metodológicos que ha habido en esa fuente, para poder establecer comparaciones homogéneas hay que tomar el año 2009 como punto de inicio de la crisis y el año 2013 como contrapunto al ser el último disponible. De ahí se deduce, como cabía esperar, que mientras el volumen de salarios se ha reducido, tanto por el descenso del número de asalariados ocupados como por la reducción de sus remuneraciones, la cuantía de las pensiones se ha elevado por el efecto conjunto del incremento de pensionistas y de la pensión media percibida.

Dicha fuente tiene la ventaja de que son datos declarados, y que en el caso de los asalariados y pensionistas es difícil el fraude fiscal puesto que son ingresos controlados por el Ministerio de Hacienda. Lo que no

\footnotetext{
${ }^{2}$ Conviene advertir que dicha fuente se refiere sólo al territorio fiscal de Régimen Común, estando excluidos, por tanto, Navarra y el País Vasco. También es importante señalar que al obtenerse los datos no sólo de los que obtienen ingresos sino de las entidades pagadoras, se incluyen también las rentas inferiores al mínimo exento que no tienen obligación de realizar la declaración del impuesto sobre la renta.
} 
permite esa fuente es comparar los ingresos derivados de cotizaciones sociales obligatorias, tanto de empresarios como de trabajadores, con los gastos en prestaciones sociales de carácter contributivo (pensiones contributivas y prestaciones por desempleo fundamentalmente). Para ello es necesario acudir a datos de la Seguridad Social y del Servicio Público de Empleo Estatal, proporcionados por el Ministerio de Empleo y Seguridad Social. En dicha fuente el problema principal es distinguir las cotizaciones correspondientes a los asalariados, y las pensiones y demás prestaciones sociales contributivas que van a parar exclusivamente a los asalariados, para poder comparar ambas. Por eso hay que recurrir a comparar las cotizaciones sociales totales, incluidas las de autónomos y demás regímenes de la seguridad social, con el total de gastos en pensiones y otras prestaciones de carácter contributivo. Las pensiones y demás prestaciones sociales no contributivas se financian con impuestos.

Es interesante tratar de confrontar los datos de asalariados que proporcionan las fuentes tributarias con los de la Encuesta de Población Activa, con el simple fin de ver el grado de discrepancia y si fuese posible apuntar las posibles causas de la misma. Análogamente, puede aportar nuevas pistas comparar los datos de pensiones y pensionistas de las fuentes tributarias con los de la Seguridad Social, aunque sólo sea para ver posibles coincidencias o discordancias. Algunos estudios han tratado de analizar la solvencia del sistema de pensiones utilizando datos de la muestra continua de vidas laborales (Rosado, 2014; Rosado y Domínguez, 2014) y aplicando un enfoque actuarial. Esa perspectiva se basa en una muestra del año 2010 y utiliza un doble enfoque, económico, vinculado a la evolución del empleo, y demográfico, teniendo en cuenta las proyecciones de población según la esperanza de vida esperada. Las conclusiones apuntan a que las cotizaciones no son capaces de cubrir las pensiones contributivas.

La complejidad del problema requiere abordarlo desde diferentes enfoques. En este artículo se opta por analizar los ciclos de creación y destrucción de empleo, vinculados a la evolución del crecimiento económico y la productividad, que son el principal condicionante de los ingresos por cotizaciones, comparándolos con los gastos en prestaciones contributivas según la tendencia derivable de su evolución en los últimos años. No se pretende analizar lo que puede ocurrir a largo plazo, dependiendo de los cambios demográficos. Se incide en que, dado el modelo productivo y de crecimiento español, lo previsible es que se repitan periodos de auge y recesión con una alta volatilidad del empleo. En las etapas de auge el empleo que se crea no logra reducir el desempleo hasta niveles manejables. Esto, junto a su carácter inestable y con tendencia a la baja de los salarios, limita el aumento de las cotizaciones. Por su parte, 
en las recesiones las tasas de paro se disparan provocando una nueva caída de las cotizaciones. Por el contrario, las prestaciones de carácter contributivo, especialmente las pensiones de jubilación, mantienen una tendencia alcista, incluso cuando se modera su crecimiento mediante distintas medidas para recortarlas y para desviar gastos hacia las prestaciones de carácter asistencial.

Se trata, por tanto, de relacionar la evolución del empleo, en cantidad y calidad, con los ingresos por cotizaciones sociales que de ello se derivan; y compararlos con los gastos en prestaciones contributivas, pensiones y desempleo fundamentalmente, que en teoría dichas contribuciones deben cubrir. Las ventajas y límites del análisis aquí utilizado es que se evita entrar en proyecciones demográficas, aunque se tienen en cuenta las consideraciones de los economistas demógrafos (Fernández Cordón, 2014; Fernández Cordón y Planelles, 2013; Conde Ruiz y González Martínez, 2013; Herce, 2013), entre los que hay conclusiones muy diversas. Al contrario de lo que es usual, analizar las consecuencias de las prestaciones sociales, y muy particularmente de las prestaciones por desempleo, sobre el empleo (Toharia, Arranz, García Serrano y Herranz, 2010), se trata de analizar los posibles efectos de las características del mercado de trabajo sobre la financiación de las prestaciones contributivas (Devesa, Domínguez y Nagore, 2013).

Sin duda la crisis y las reformas del mercado de trabajo y de las pensiones, en especial la reforma de 2012, han condicionado decisivamente los cambios en el empleo y en las prestaciones contributivas (Consejo Económico y Social, 2015; García Pérez, 2015; Galiana, 2013; y Calvo Gallego, 2013, a y b). Sin embargo, el planteamiento de partida es que más allá de la crisis y las reformas, el modelo productivo y de crecimiento es el determinante fundamental del empleo, que a su vez es el principal condicionante de las cotizaciones. La crisis y las reformas que se están imponiendo como respuesta a la misma no modifican dicho modelo de crecimiento (Palacio, 2012 y 2013). De ahí que la recuperación del empleo, por su precariedad, difícilmente puede servir para sostener los gastos en prestaciones contributivas. Además, ante cualquier impacto que provoque una nueva recesión resulta razonable esperar que vuelva a producirse una destrucción de empleo rápida e intensa como la que se ha producido en la última crisis y en anteriores recesiones.

Tras esta introducción en el siguiente apartado se aportan datos generales del mercado de trabajo, tratando de mostrar algunas de las características persistentes a lo largo del tiempo, como son las elevadas tasas de desempleo y temporalidad, y las fluctuaciones en las tasas de actividad y de empleo, así como en el nivel y evolución de la 
productividad. A continuación se dedica un epígrafe a examinar los cambios en la cuantía de los salarios, las pensiones y las prestaciones por desempleo, tomando como referencia los datos de las fuentes tributarias en 2009 y 2013. En un apartado adicional se analizan los datos de la Seguridad Social de cotizaciones sociales y prestaciones contributivas, referidos a esos mismos años, 2009 y 2013. Se cierra con unas conclusiones que pretenden destacar los hallazgos derivados de los datos examinados y las incógnitas que se desprenden se las discordancias existentes entre distintas fuentes, haciendo hincapié en las perspectivas de futuro.

\section{Persistencias y cambios cíclicos en el mercado de trabajo español}

La economía española ha generado normalmente poco empleo. Cuando se han conseguido aumentos significativos, como en el periodo 1998-2007, el empleo creado ha tenido características que le han hecho muy vulnerable. Eso explica que la tasa de paro esté siempre por encima de la media europea y que en la mayoría de los años, desde que existen datos comparativos, haya duplicado aproximadamente dicha media (gráfico 1).

Esto ha venido además acompañado de una tasa de temporalidad también muy alejada de la media europea (Toharia, 2005), llegando incluso a triplicarla (cuadro 1). Con la crisis se ha rebajado inicialmente la tasa de temporalidad porque es el empleo que antes se destruye. Las últimas reformas laborales han tratado de reducir la tasa de temporalidad, pero sus efectos han sido muy escasos (Cebrián y Moreno, 2012). Lo que sí se ha conseguido es una reducción de las indemnizaciones por despido y un descenso de los salarios. En vez de mejorar las condiciones de trabajo del conjunto se han deteriorado, incluyendo a buena parte de los trabajadores con contrato fijo. Se ha logrado abaratar la contratación y el despido, aunque se tenga un contrato fijo. Algunas de las nuevas figuras como la del contrato de emprendedores favorecen esta confluencia entre los contratados temporales y fijos. Esto no impide que se siga recurriendo en un alto porcentaje a la contratación temporal, todavía muy por encima de la media europea.

Recientemente también ha habido un acercamiento a la media europea en cuanto a porcentaje de empleo a tiempo parcial (cuadro 1). Se ha señalado a veces que la alta temporalidad era la contrapartida del menor porcentaje de empleo a tiempo parcial. No es exactamente así. Hay mayor propensión a que haya empleo a tiempo parcial voluntario en 
sistemas productivos más flexibles. La mayor rigidez de los sistemas de organización del trabajo en España ha hecho que se recurra menos al empleo a tiempo parcial. El progresivo aumento de los últimos años de la contratación a tiempo parcial es la consecuencia de utilizar un recurso adicional de reducción de los costes de la mano de obra, más que un signo de mayor flexibilidad. Una prueba de ello es que la mayoría de los trabajadores a tiempo parcial manifiestan que es algo no deseado por ellos, al contrario de lo que ocurre en los demás países europeos con tasas más elevadas de empleo a tiempo parcial.

\section{Gráfico 1. Tasa de paro}

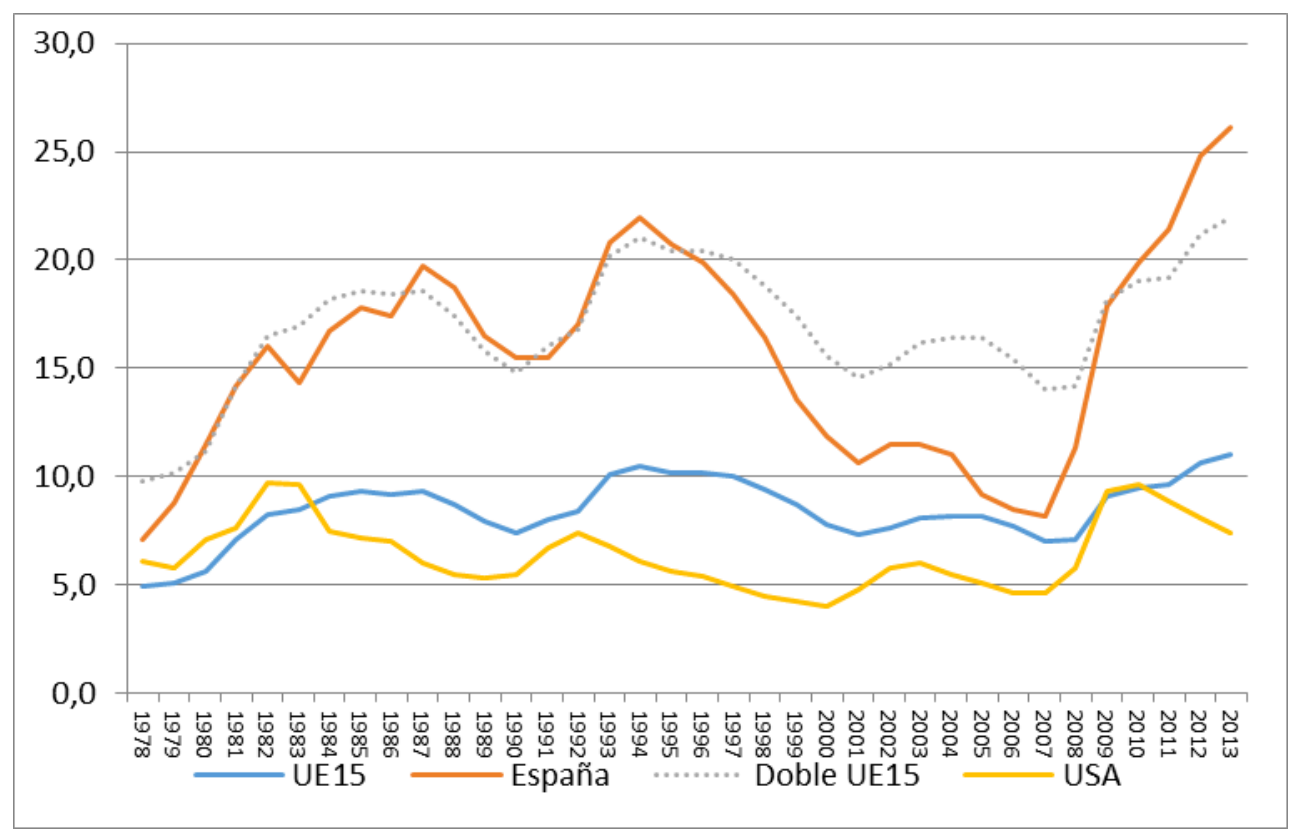

Fuente: Elaboración propia a partir de datos de Eurostat.

La precariedad del empleo acaba por afectar al rendimiento de la fuerza de trabajo. Hay escasos incentivos para mejorar dicho rendimiento y los trabajadores, en vez de acumular experiencia y reciclarse para elevar su cualificación, ven como se deterioran sus conocimientos. De ahí que, a pesar de la incorporación de nuevas tecnologías, la productividad tienda a frenarse. Se establece así un círculo vicioso en el que el menor crecimiento de la productividad conduce a reducir los salarios para ajustarlos a dicho 
crecimiento y así sucesivamente. Sólo se consiguen aumentos de productividad cuando en las recesiones hay una rápida e intensa reducción del empleo, como ha ocurrido en los comienzos de la actual crisis. Al ser muy superior la caída del empleo que la del PIB, hay un súbito aumento de la productividad. No se da, sin embargo, un incremento de los salarios y demás costes laborales paralelo al de la productividad. Esto se justifica por la conveniencia de recuperar beneficios para favorecer la inversión y mejorar el empleo, así como la competitividad de la economía española. Sin embargo, más que en otras ocasiones, la contención salarial vinculada a la precariedad del empleo creado, así como la persistencia de una tasa de paro muy elevada, provocan que haya una recuperación de la demanda interna (consumo e inversión) muy limitada.

Cuadro 1. Tasas de empleo temporal y a tiempo parcial

\begin{tabular}{cccccccc}
\hline & & $\mathbf{2 0 0 2}$ & $\mathbf{2 0 0 5}$ & $\mathbf{2 0 0 8}$ & $\mathbf{2 0 1 1}$ & $\mathbf{2 0 1 2}$ & $\mathbf{2 0 1 3}$ \\
\hline \multirow{2}{*}{ TASA DE EMPLEO } & UE28 & 12,4 & 14,0 & 14,1 & 14,0 & 13,6 & 13,7 \\
TEMPORAL & AE18 & 14,6 & 16,0 & 16,1 & 15,7 & 15,1 & 15,1 \\
& ESPAÑA & 32,3 & 33,4 & 29,2 & 25,2 & 23,4 & 23,2 \\
\hline \multirow{2}{*}{ TASA DE EMPLEO A } & UE28 & 15,6 & 17,2 & 17,5 & 18,7 & 19,1 & 19,6 \\
TIEMPO PARCIAL & AE18 & 15,7 & 18,0 & 18,8 & 20,3 & 20,8 & 21,6 \\
& ESPAÑA & 8,0 & 12,0 & 11,6 & 13,5 & 14,4 & 15,7 \\
\hline
\end{tabular}

Fuente: Eurostat.

Son también significativas las fluctuaciones en las tasas de actividad y empleo, y en la evolución de la productividad. La tasa de actividad en España, que estaba por debajo de la media europea, se va acercando hasta superarla (cuadro 2). En los años de crisis, a pesar del aumento de los "desanimados" por efecto del alto nivel de desempleo y el incremento del paro de larga duración, el descenso de los ingresos de buena parte de las familias, más intenso en España, ha provocado que se persista en conseguir un empleo aceptando condiciones inadmisibles ${ }^{3}$. La tasa de actividad se mantiene por encima de la media europea.

La tasa de empleo, que de algún modo es el reverso de la tasa de paro, indica claramente no sólo que siempre se mantiene por debajo de la media europea, sino que tiene mayores fluctuaciones (cuadro 2). En las etapas de expansión se crea empleo con mayor facilidad, al ser éste de carácter esencialmente precario, aunque no se logre alcanzar los niveles de los países más avanzados. Esa precariedad explica igualmente que, con

\footnotetext{
${ }^{3}$ La OIT ha reclamado la necesidad de garantizar un "trabajo decente”. Véase OIT (2014).
} 
igual o mayor facilidad que se crea, se destruye empleo en las recesiones. La tasa de empleo se distancia cada vez más del conjunto europeo durante la crisis y aunque con la recuperación económica en el último año vuelve a crecer, ratificando la tendencia ya señalada, sigue estando muy por debajo de la media europea y del nivel previo a la crisis.

Cuadro 2. Tasas de actividad y de empleo

\begin{tabular}{cccccccc}
\hline & & $\mathbf{2 0 0 2}$ & $\mathbf{2 0 0 5}$ & $\mathbf{2 0 0 8}$ & $\mathbf{2 0 1 1}$ & $\mathbf{2 0 1 2}$ & $\mathbf{2 0 1 3}$ \\
\hline \multirow{2}{*}{ TASA DE } & UE28 & 68,6 & 69,7 & 70,7 & 71,1 & 71,7 & 71,9 \\
ACTIVIDAD & AE18 & 68,2 & 69,9 & 71,3 & 71,5 & 72,0 & 72,2 \\
& ESPAÑA & 66,4 & 70,0 & 72,7 & 73,9 & 74,3 & 74,3 \\
\hline \multirow{2}{*}{ TASA DE } & UE28 & 62,3 & 63,4 & 65,7 & 64,1 & 64,1 & 64,1 \\
EMPLEO & AE18 & 62,3 & 63,6 & 65,9 & 64,2 & 63,8 & 63,5 \\
& ESPAÑA & 59,0 & 63,6 & 64,5 & 58,0 & 55,8 & 54,8 \\
\hline
\end{tabular}

Fuente: Eurostat.

Las fluctuaciones en el empleo y su alto grado de precariedad se reflejan en la evolución de la productividad (gráfico 2). Hay una clara asimetría entre el conjunto de la Unión Europea y España. Mientras que en España tiende a estancarse e incluso descender en la etapa de expansión, la media europea mantiene tasas positivas de crecimiento de la productividad. Al llegar la crisis el rápido descenso del empleo, muy superior a la caída del PIB, provoca en España un súbito incremento de la productividad, al contrario que en Europa. En 2010 el conjunto de Europa aumenta el PIB en mayor proporción que el empleo, lo que explica el fuerte crecimiento de su productividad, mientras que en España sigue predominando la destrucción de empleo. Posteriormente la Unión Europea recupera empleo con mayor intensidad que en España, lo que reduce el crecimiento de su productividad. A partir de 2013 empieza a recuperarse la tendencia a que en España se reduzca el crecimiento de su productividad conforme empieza a crear empleo.

La última reforma laboral en curso en España ha permitido abaratar notablemente el coste de la fuerza de trabajo. Si con anterioridad la principal vía de abaratamiento era la contratación temporal, la reforma laboral ha añadido la reducción de las indemnizaciones por despido y la creación de nuevos tipos de contratación, como el de apoyo a los emprendedores, que deprecian el contrato fijo. En esa misma dirección han ido los cambios en la regulación de la negociación colectiva, tendiendo a reducir el poder negociador de los sindicatos, especialmente en el segmento de las pequeñas y medianas empresas, así como la ampliación 
del poder discrecional del empresario para modificar las condiciones de trabajo. Más allá de la reducción generalizada de los salarios y demás condiciones de trabajo, lo que se plantea es si ese modelo laboral es sostenible en relación con el sistema de protección social que se ha desarrollado. Es previsible que se vuelva a frenar el crecimiento de la productividad y se mantengan salarios notablemente más bajos que los que había antes de la crisis. De ahí que, sin un aumento drástico de la tasa de empleo, difícilmente las cotizaciones sociales, que se derivan de ese nivel de remuneraciones, pueden cubrir las prestaciones sociales de carácter contributivo, que dichas cotizaciones se supone deben financiar.

\section{Gráfico 2. Evolución de la productividad del trabajo (\% cambio anual del PIB por ocupado)}

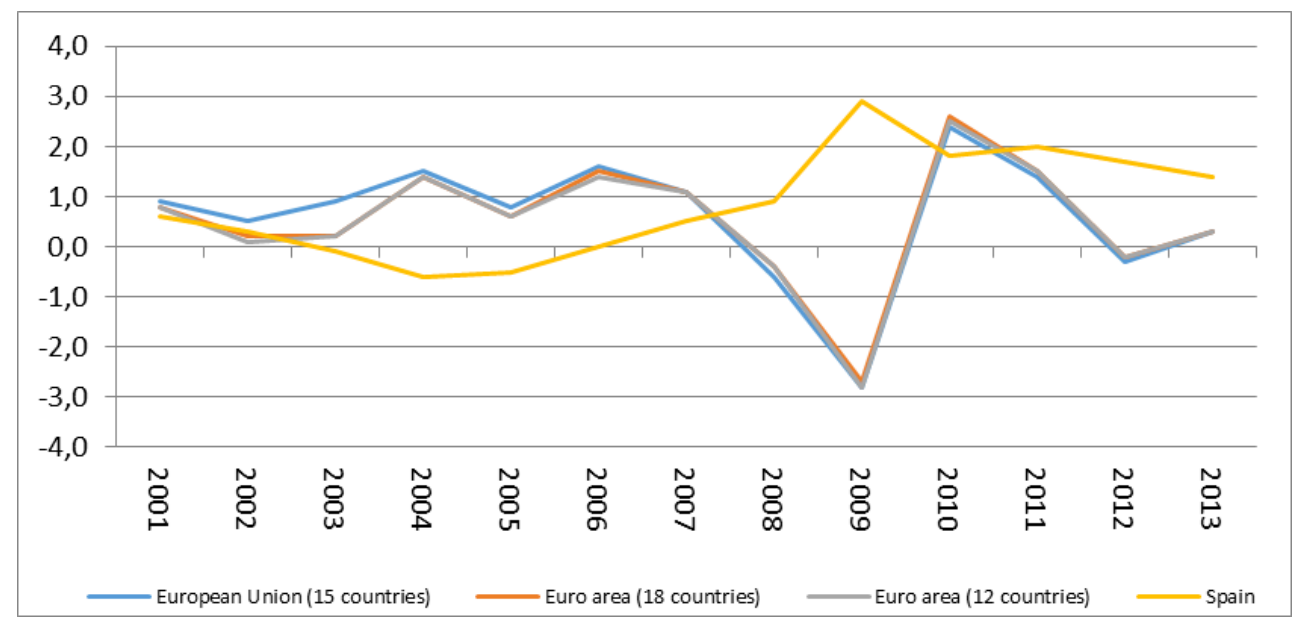

Fuente: Elaboración propia a partir de datos de Eurostat

En el siguiente epígrafe se trata precisamente de examinar que cambios ha habido en las remuneraciones, prestando atención a si han afectado igualmente a los distintos niveles salariales, y si esos cambios han reducido hasta tal punto las cotizaciones que éstas no pueden cubrir los gastos en pensiones contributivas y en prestaciones por desempleo. 


\section{Salarios y prestaciones sociales de carácter contributivo}

Se analizan los cambios en los salarios, las pensiones y las prestaciones por desempleo. A continuación se compara la evolución en las cotizaciones sociales obligatorias y en las prestaciones sociales de carácter contributivo para ver en qué medida las cotizaciones cubren dichas prestaciones. Se toman como referencia los años 2009 y 2013. La limitación viene impuesta por razones de homogeneidad de la fuente utilizada para analizar los salarios y las pensiones, que es la estadística de salarios y pensiones de la Agencia Tributaria. En todo caso, aunque en 2009 ya ha habido una importante caída del empleo, los salarios todavía no han iniciado un claro descenso. Entre 2009 y 2013 las retribuciones salariales descienden (cuadros 3 y 4). Es una consecuencia tanto de la reducción en el número de asalariados y perceptores, como del salario medio percibido. La destrucción de empleo, aunque ha afectado tanto a no asalariados como a asalariados, ha sido más intensa entre estos últimos. A pesar de que ha disminuido más el número de asalariados con contrato temporal, que tienen remuneraciones inferiores a los fijos, la caída del salario medio indica que la reducción salarial se ha dado también en los trabajadores fijos.

\section{Cuadro 3. Retribuciones salariales (euros) y número de asalariados}

\begin{tabular}{|c|c|c|c|}
\hline & 2009 & 2013 & $\begin{array}{c}\text { \% variación } \\
2013-2009\end{array}$ \\
\hline Retribuciones totales & 352.145 .124 .910 & 308.697 .553 .706 & $-12,3$ \\
\hline Perceptores & $\begin{array}{r}23.328 .3 \\
71\end{array}$ & 21.077.382 & $-9,6$ \\
\hline Asalariados & $\begin{array}{r}18.451 .8 \\
27\end{array}$ & 16.682 .061 & $-9,6$ \\
\hline Retribución media & $15.095,1$ & $14.645,9$ & $-3,0$ \\
\hline Salario medio & 19.085 & 18.505 & $-3,0$ \\
\hline
\end{tabular}

Fuente: Salarios y pensiones en las fuentes tributarias

En cualquier caso, dicha reducción salarial no es proporcional para todos los trabajadores, de forma que se ha producido un aumento de la desigualdad. En conjunto la retribución media ha descendido alrededor de 
un 3 por ciento. En todos los tramos de empresas de menos de 100 trabajadores la retribución media se reduce, mientras que en los de 100 o más trabajadores aumenta (cuadro 5). Por tanto, cuando se afirma que ha habido una reducción de salarios hay que tener en cuenta que ésta no ha afectado por igual a todos los trabajadores y que en las empresas más grandes, que ya partían de salarios más elevados, los salarios han aumentado. El número de perceptores disminuye más en las empresas medianas y grandes, las de salarios más elevados, que en las pequeñas (efecto composición). No obstante, el aumento de la retribución media en las empresas de mayor tamaño determina que en esos tramos el total de retribuciones caiga en menos proporción.

\section{Cuadro 4. Retribuciones salariales (millones de euros), empleo total y asalariado (miles) y número de horas trabajadas}

\begin{tabular}{cccc}
\hline & 2009 & $\mathbf{2 0 1 3}$ & $\begin{array}{c}\text { \% } \\
\text { 2013-2009 }\end{array}$ \\
\hline Remuneración de asalariados & 549.173 & 490.253 & $-10,7$ \\
Sueldos y salarios & 436.307 & 385.898 & $-11,6$ \\
Puestos de trabajo totales & $20.811,4$ & 18602,7 & $-10,6$ \\
$\begin{array}{c}\text { Puestos de trabajo asalariados } \\
\text { Personas totales (Ocupados) }\end{array}$ & $18.066,1$ & $15.992,7$ & $-11,5$ \\
$\begin{array}{c}\text { Personas asalariadas } \\
\text { (Asalariados) }\end{array}$ & $19.986,8$ & $17.947,8$ & $-10,2$ \\
Empleo equivalente a tiempo & 17317,5 & $15.389,4$ & $-11,1$ \\
$\begin{array}{c}\text { completo total } \\
\text { Empleo equivalente a tiempo } \\
\text { completo asalariado } \\
\text { Horas totales }\end{array}$ & $18.642,1$ & $16.350,8$ & $-12,3$ \\
$\quad$ Horas asalariadas & $16.132,1$ & $13.980,2$ & $-13,3$ \\
\hline
\end{tabular}

Fuente: Contabilidad Nacional, INE.

Las diferencias salariales y su desigual evolución es aún más evidente si se consideran tramos salariales, definidos en relación al salario mínimo vigente cada año (cuadro 6). De nuevo se comprueba que el descenso en los salarios totales no es sólo la consecuencia de la reducción del número de asalariados sino también de la caída del salario medio en el tramo inferior (0 a 0,5 SMI), que es también el único en el que el número de asalariados aumenta y además de forma muy notable. Las 
percepciones por persona aumentan tan sólo en los dos escalones inferiores, disminuyendo en todos los demás y siendo constantes a escala agregada.

\begin{tabular}{|c|c|c|c|c|}
\hline amaños de empresa & Años & Retribución media & Retribuciones & Perceptores \\
\hline \multirow{3}{*}{ Total } & 2009 & $15.095,1442$ & 352.145 .124 .910 & 23.328 .371 \\
\hline & 2013 & $14.645,9154$ & 308.697 .553 .706 & 21.077 .382 \\
\hline & \% Variación & $-2,98$ & $-12,34$ & $-9,65$ \\
\hline \multirow{3}{*}{1 a 3} & 2009 & $10.180,8395$ & 16.687 .291 .855 & 1.639 .088 \\
\hline & 2013 & $9.344,6065$ & 14.898 .405 .164 & 1.594 .332 \\
\hline & \% Variación & $-8,21$ & $-10,72$ & $-2,73$ \\
\hline \multirow{3}{*}{4 a 9} & 2009 & $10.574,1024$ & 27.375 .991 .569 & 2.588 .966 \\
\hline & 2013 & $9.349,03082$ & 22.952 .366 .158 & 2.455 .053 \\
\hline & \% Variación & $-11,59$ & $-16,16$ & $-5,17$ \\
\hline \multirow{3}{*}{10 a 19} & 2009 & $11.168,1259$ & 25.578 .012 .556 & 2.290 .269 \\
\hline & 2013 & $9.777,17775$ & 20.604.786.137 & 2.107 .437 \\
\hline & \% Variación & $-12,45$ & $-19,44$ & $-7,98$ \\
\hline \multirow{3}{*}{20 a 49} & 2009 & $12.290,0517$ & 35.102 .427 .668 & 2.856 .166 \\
\hline & 2013 & $11.268,9482$ & 28.094 .299 .144 & 2.493 .072 \\
\hline & \% Variación & $-8,31$ & $-19,96$ & $-12,71$ \\
\hline \multirow{3}{*}{50 a 99} & 2009 & $13.343,4844$ & 24.914 .313 .540 & 1.867 .152 \\
\hline & 2013 & $13.004,3271$ & 21.163.996.118 & 1.627 .458 \\
\hline & \% Variación & $-2,54$ & $-15,05$ & $-12,84$ \\
\hline \multirow{3}{*}{100 a 199} & 2009 & $14.117,3895$ & 23.072.925.016 & 1.634 .362 \\
\hline & 2013 & $14.337,7373$ & 20.532.543.088 & 1.432 .063 \\
\hline & \% Variación & 1,56 & $-11,01$ & $-12,38$ \\
\hline \multirow{3}{*}{200 a 499} & 2009 & $15.219,694$ & 29.477 .914 .261 & 1.936 .827 \\
\hline & 2013 & $15.716,1255$ & 27.195.702.229 & 1.730 .433 \\
\hline & \% Variación & 3,26 & $-7,74$ & $-10,66$ \\
\hline \multirow{3}{*}{500 o más } & 2009 & $19.956,0132$ & 169.936 .248 .446 & 8.515 .541 \\
\hline & 2013 & $20.066,0914$ & 153.255 .455 .668 & 7.637 .534 \\
\hline & \% Variación & 0,55 & $-9,82$ & $-10,31$ \\
\hline
\end{tabular}

Fuente: Elaboración propia a partir de "Mercado de trabajo y pensiones en las fuentes tributarias", Agencia Tributaria.

Notas: Los tamaños de empresa se refieren a número de trabajadores. El número de perceptores de salarios no coincide con el número de asalariados (véase siguiente cuadro) puesto que hay asalariados que perciben más de un salario.

El aumento del peso relativo de los asalariados con menores retribuciones, junto a la reducción de su salario medio, explica que, a pesar de que en los demás tramos el salario medio crece, a escala agregada disminuya. Además, el número de asalariados en algunos de los tramos de salarios más bajos (0,5 a 1; 3 a 3,5; y 3,5 a 4 SMI) se reduce menos que la media, mientras que donde más cae el número de 
asalariados es en los cuatro tramos más altos, sobrepasando el 20 por ciento de caída. Existe pues una clara diferenciación salarial, que se ha incrementado aún más durante la crisis. El salario medio del tramo superior equivale a 74,3 veces el del tramo inferior en 2009, elevándose dicha proporción a 81,5 en 2013. Mientras que en el tramo superior crecía algo más del 6 por ciento, en el tramo inferior se reducía un 3,4 por ciento en dicho periodo. No cabe por tanto limitarse a constatar que se ha producido una caída de los salarios y de la participación de las rentas salariales en el valor añadido, como suele hacerse. La reducción salarial se ha concentrado en el tramo de salarios más bajos, que es además el único donde se ha incrementado significativamente el número de asalariados. En el resto de tramos ha habido un aumento en torno al 3 por ciento en esos cuatro años, con la excepción del tramo superior que, como ya se ha destacado, supera el 6 por ciento.

Esto se refleja de forma sintética en los índices de desigualdad (Gini y Theil), referidos a la retribución media por tamaño de empresa y el salario medio según tramos de salario (cuadro 7). Más que el valor absoluto de esos índices, que varía según el número de segmentos que se consideren y la amplitud y homogeneidad o no homogeneidad de los mismos, es significativa su evolución. También la intensidad de la misma depende del grado de desagregación. En el caso de la distribución por tramos de salario, el índice de Theil indica incluso una disminución de la desigualdad y el índice de Gini muestra un aumento de la desigualdad muy pequeño. Estos resultados nos hacen ver que cuando existen importantes diferencias salariales, como ocurre en este caso, la evolución de los salarios a escala agregada y de la desigualdad salarial requiere un análisis detallado de la estructura salarial desde diferentes parámetros o puntos de vista.

Lo que es indudable es que ha habido un descenso de salarios y que éste ha afectado, sobre todo, a los niveles salariales inferiores. Las remuneraciones en las empresas con menos de cien trabajadores, que están por debajo de la media, se han reducido; mientras que en las empresas de mayor tamaño se han incrementado. Señalar, por tanto, que ha habido una caída de los salarios sin tener en cuenta esta asimetría implica ignorar que eso no significa que todos los salarios disminuyan. Precisamente lo que ocurre es que se contraen los salarios más bajos y se acrecientan los más altos. Estos últimos se corresponden con empresas que no sólo son más grandes sino que en muchos casos están menos expuestas a la competencia. Es decir, las diferencias salariales y la tendencia a una creciente desigualdad responden a la estructura y funcionamiento del tejido productivo que determina la demanda de trabajo. 


\section{Cuadro 6. Salarios (euros) y asalariados por tramos de salario}

\begin{tabular}{|c|c|c|c|c|c|}
\hline $\begin{array}{c}\text { Tramos de } \\
\text { salario }\end{array}$ & Años & $\begin{array}{c}\text { Salario medio } \\
\text { anual }\end{array}$ & Salarios & Asalariados & $\begin{array}{c}\text { Percepciones por } \\
\text { persona }\end{array}$ \\
\hline \multirow{3}{*}{ Total } & 2009 & 19.085 & 352.145 .124 .910 & 18.451 .827 & 1,26 \\
\hline & 2013 & 18.505 & 308.695 .720 .646 & 16.682 .061 & 1,26 \\
\hline & \% Variación & $-3,04$ & $-12,34$ & $-9,59$ & 0 \\
\hline \multirow{3}{*}{0 a $0,5 \mathrm{SMI}$} & 2009 & 1.871 & 6.371 .007 .094 & 3.405 .089 & 1,36 \\
\hline & 2013 & 1.808 & 6.586 .044 .424 & 3.642 .236 & 1,42 \\
\hline & \% Variación & $-3,37$ & 3,38 & 6,96 & 4,41 \\
\hline \multirow{3}{*}{ 0,5 a $1 \mathrm{SMI}$} & 2009 & 6.523 & 14.684 .199 .197 & 2.251 .294 & 1,49 \\
\hline & 2013 & 6.738 & 14.216 .238 .189 & 2.109 .804 & 1,50 \\
\hline & \% Variación & 3,30 & $-3,19$ & $-6,28$ & 0,67 \\
\hline \multirow{3}{*}{$1 \mathrm{~A} 1,5 \mathrm{SMI}$} & 2009 & 10.993 & 25.106 .644 .263 & 2.283 .950 & 1,35 \\
\hline & 2013 & 11.336 & 22.464 .353 .240 & 1.981 .641 & 1,32 \\
\hline & \% Variación & 3,12 & $-10,52$ & $-13,24$ & $-2,22$ \\
\hline \multirow{3}{*}{1,5 a $2 \mathrm{SMI}$} & 2009 & 15.282 & 40.926 .651 .473 & 2.678 .098 & 1,20 \\
\hline & 2013 & 15.820 & 35.190 .625 .871 & 2.224 .493 & 1,18 \\
\hline & \% Variación & 3,52 & $-14,02$ & $-16,94$ & $-1,67$ \\
\hline \multirow{3}{*}{2 a $2,5 \mathrm{SMI}$} & 2009 & 19.507 & 39.756 .020 .645 & 2.038 .056 & 1,16 \\
\hline & 2013 & 20.177 & 35.558 .226 .832 & 1.762 .320 & 1,14 \\
\hline & \% Variación & 3,43 & $-10,56$ & $-13,53$ & $-1,72$ \\
\hline \multirow{3}{*}{2,5 a $3 \mathrm{SMI}$} & 2009 & 23.865 & 34.117 .876 .767 & 1.429 .632 & 1,15 \\
\hline & 2013 & 24.730 & 30.925 .391 .161 & 1.250 .515 & 1,11 \\
\hline & \% Variación & 3,62 & $-9,36$ & $-12,53$ & $-3,48$ \\
\hline \multirow{3}{*}{3 a $3,5 \mathrm{SMI}$} & 2009 & 28.338 & 29.697 .044 .937 & 1.047 .968 & 1,17 \\
\hline & 2013 & 29.262 & 28.806 .759 .265 & 984.453 & 1,10 \\
\hline & \% Variación & 3,26 & $-3,00$ & $-6,06$ & $\begin{array}{r}1,10 \\
-5,98\end{array}$ \\
\hline \multirow{3}{*}{3,5 a 4 SMI } & 2009 & 32.670 & 27.164 .269 .158 & 831.484 & 1,14 \\
\hline & 2013 & 33.787 & 25.710 .354 .914 & 760.957 & 1,10 \\
\hline & \% Variación & 3,42 & $-5,35$ & $-8,48$ & $-3,51$ \\
\hline \multirow{3}{*}{4 a $4,5 \mathrm{SMI}$} & 2009 & 37.023 & 24.203 .313 .707 & 653.736 & 1,13 \\
\hline & 2013 & 38.248 & 21.671 .203 .381 & 566.591 & 1,10 \\
\hline & \% Variación & 3,31 & $-10,46$ & $-13,33$ & $-2,65$ \\
\hline \multirow{3}{*}{4,5 a $5 \mathrm{SMI}$} & 2009 & 41.347 & 20.581 .092 .461 & 497.768 & 1,12 \\
\hline & 2013 & 42.742 & 15.258 .058 .561 & 356.983 & 1,11 \\
\hline & \% Variación & 3,37 & $-25,86$ & $-28,28$ & $-0,89$ \\
\hline \multirow{3}{*}{5 a $7,5 \mathrm{SMI}$} & 2009 & 51.860 & 47.508 .999 .657 & 916.101 & 1,15 \\
\hline & 2013 & 53.894 & 38.910 .760 .528 & 721.985 & 1,13 \\
\hline & \% Variación & 3,92 & $-18,10$ & $-21,19$ & $-1,74$ \\
\hline \multirow{3}{*}{7,5 a $10 \mathrm{SMI}$} & 2009 & 74.504 & 18.658 .065 .404 & 250.431 & 1,18 \\
\hline & 2013 & 76.733 & 14.954 .555 .013 & 194.892 & 1,16 \\
\hline & \% Variación & 2,99 & $-19,85$ & $-22,18$ & $-1,69$ \\
\hline \multirow{3}{*}{ Más de 10 SMI } & 2009 & 138.926 & 23.369 .940 .147 & 168.218 & 1,22 \\
\hline & 2013 & 147.320 & 18.443 .149 .268 & 125.191 & 1,19 \\
\hline & \% Variación & 6,04 & $-21,08$ & $-25,58$ & $-2,46$ \\
\hline
\end{tabular}

Fuente: Elaboración propia a partir de "Mercado de trabajo y pensiones en las fuentes tributarias", Agencia Tributaria.

Notas: SMI = Salario Mínimo Interprofesional. En 2009 SMI = 8736 euros anuales; en 2013 SMI $=9034,20$ euros anuales. El incremento del SMI entre ambos años es del 3,4\%. Las percepciones por persona resultan de dividir el número de percepciones por el de asalariados. 


\section{Cuadro 7. Índices de desigualdad salarial}

\begin{tabular}{cccc}
\hline & & $\begin{array}{c}\text { RETRIBUCIONES POR } \\
\text { TAMANO DE } \\
\text { ESTABLECIMIENTO }\end{array}$ & $\begin{array}{c}\text { RETRIBUCIONES } \\
\text { POR TRAMOS DE } \\
\text { SALARIO }\end{array}$ \\
\hline \multirow{3}{*}{ GINI } & 2009 & 0,1429 & 0,4613 \\
& 2013 & 0,1689 & 0,4764 \\
& \% VARIACIÓN & 18,2 & 3,3 \\
\hline \multirow{3}{*}{ THEIL } & 2009 & 0,3908 & 0,0869 \\
& 2013 & 0,4154 & 0,0839 \\
& \% VARIACIÓN & 6,3 & $-3,5$ \\
\hline
\end{tabular}

Fuente: Elaboración propia a partir de los datos de "Mercado de trabajo y pensiones en las fuentes tributarias", Agencia Tributaria (véase cuadros 5 y 6 )

Por su parte, los salarios ínfimos, correspondientes al tramo de 0 a 0,5 salario mínimo, han afectado a un mayor número de trabajadores, y son, precisamente, los únicos que se han reducido. Esto apunta a que la devaluación salarial no sólo responde al deterioro de las remuneraciones en las empresas de menor tamaño sino que se debe, sobre todo, a una expansión de los contratos de corta duración y a tiempo parcial, lo que implica que muchos trabajadores tienen un salario anual muy por debajo del salario mínimo. Si en 2009 dicho porcentaje era del 30,7 por ciento, en 2013 se ha incrementado hasta el 34,4 por ciento; y los que ni siquiera llegan a la mitad del salario mínimo han pasado de representar el 18,5 por ciento de los asalariados en 2009 al 21,8 por ciento en 2013. Aunque ha aumentado la desigualdad entre el extremo superior (más de $10 \mathrm{SMI}$ ) y el inferior (0 a 0,5 SMI), en el conjunto de la distribución apenas ha variado e incluso, según el índice de Theil, ha disminuido.

Esto tiene una implicación si cabe más importante que la que se deriva de la dinámica de remuneraciones según tamaños de empresa. La mayoría de los trabajadores ha tenido un ligero incremento salarial entre 2009 y 2013, algo superior al 3 por ciento, que en todo caso queda por debajo del de los precios de consumo. Sin embargo, en el tramo salarial inferior (0 a 0,5 SMI), que supone algo más del 20 por ciento de los asalariados en 2013, el salario medio ha descendido. En el otro extremo, el escalón superior (más de $10 \mathrm{SMI}$ ), que representa un 0,8 del total de asalariados en 2013, frente al 1,8 que representaba en 2009, aumenta sus salarios en ese periodo algo más del 6 por ciento. Se explica así que, a pesar de que la mayoría de los trabajadores ha incrementado su salario, a escala agregada el salario medio se reduzca; y que aunque ha aumentado notablemente la desigualdad entre extremos, ésta no ha variado casi e incluso ha disminuido en el conjunto de la distribución. 
Tener en cuenta estas desigualdades es fundamental a la hora de ver los efectos de la reducción salarial sobre las cotizaciones. El incremento en el peso relativo de los niveles salariales más bajos es la causa principal del descenso de la cuantía de las cotizaciones sociales. Una recuperación del empleo que acentúa aún más el desfase entre las remuneraciones más altas, que pierden peso relativo, y las más bajas, que lo ganan, implica que la recaudación por cotizaciones sociales crezca en menor proporción que el empleo. La reivindicación de que se creen puestos de trabajo con mayor estabilidad y mejor remunerados requiere remodelaciones de la estructura productiva que sólo se pueden alcanzar introduciendo una mayor competencia que favorezca la mejora de la productividad. De lo contrario, las empresas con mayor poder de mercado, que representan un porcentaje de empleo relativamente reducido, elevarán sus remuneraciones, pero la mayor parte del tejido empresarial únicamente logrará sobrevivir a base de crear empleos precarios incapaces de sostener la financiación de las prestaciones sociales contributivas.

En contraste con la reducción de la masa salarial que condiciona los ingresos por cotizaciones, las pensiones y las prestaciones por desempleo, que constituyen el gasto en prestaciones sociales contributivas, se ha incrementado. La pensión media (PM) anual, al contrario de lo que ocurre con el salario, se ha elevado en el periodo 2009 a 2013 en un 14 por ciento (cuadro 8).

El número pensionistas ha aumentado alrededor del 3 por ciento en ese mismo periodo. Al considerar la distribución por tramos de pensión se observa que el número de pensionistas ha disminuido en los extremos y ha aumentado en los tramos intermedios. La pensión media se ha incrementado en casi todos los tramos entre el 7 y el 9 por ciento. Tan sólo en los intervalos de 1 a 1,5 y de 4,5 a 5 PM ha crecido por encima y en el de más de 10 PM muy por debajo. En todo caso la evolución de la pensión media es el resultado de los cambios tanto en el número de pensionistas como en el de pensiones por persona en cada uno de los tramos. En general las pensiones por persona se han reducido más en los tramos superiores, a partir del de 3 a 3,5 PM, y menos, e incluso han aumentado, en los inferiores. 
106 Palacio Morena \& Aragón Medina /Revista de Economía Laboral 12 (2015), 88-127

\section{Cuadro 8. Pensiones (euros) y pensionistas por tramos de} pensión.

\begin{tabular}{|c|c|c|c|c|c|}
\hline $\begin{array}{c}\text { Tramos de } \\
\text { salario }\end{array}$ & Años & $\begin{array}{c}\text { Pensión } \\
\text { media } \\
\text { anual }\end{array}$ & Total pensiones & Pensionistas & $\begin{array}{l}\text { Pensiones } \\
\text { por persona }\end{array}$ \\
\hline \multirow[t]{3}{*}{ Total } & 2009 & 11.364 & 102.232 .884 .984 & 8.996 .206 & 1,14 \\
\hline & 2013 & 12.954 & 120.146 .484 .624 & 9.274 .856 & 1,13 \\
\hline & \% Variación & 13,99 & 17,52 & 3,10 & $-0,88$ \\
\hline \multirow[t]{3}{*}{0 a $0,5 \mathrm{PM}$} & 2009 & 1.503 & 1.960 .779 .231 & 1.304 .577 & 1,03 \\
\hline & 2013 & 1.637 & 1.942 .436 .371 & 1.186 .583 & 1,04 \\
\hline & \% Variación & 8,92 & $-0,94$ & $-9,04$ & 0,97 \\
\hline 0,5 a 1 & 2009 & 5.858 & 7.996.117.278 & 1.364 .991 & 1,04 \\
\hline \multirow[t]{2}{*}{ PM } & 2013 & 6.381 & 8.199.259.569 & 1.284 .949 & 1,06 \\
\hline & \% Variación & 8,93 & 2,54 & $-5,86$ & 1,92 \\
\hline $1 \mathrm{~A} 1,5$ & 2009 & 8.704 & 29.891.276.800 & 3.434 .200 & 1,05 \\
\hline \multirow[t]{2}{*}{$\mathrm{PM}$} & 2013 & 9.591 & 33.636.059.004 & 3.507 .044 & 1,05 \\
\hline & \% Variación & 10,19 & 12,53 & 2,12 & 0 \\
\hline 1,5 a 2 & 2009 & 13.220 & 12.152 .564 .320 & 919.256 & 1,16 \\
\hline \multirow[t]{2}{*}{ PM } & 2013 & 14.382 & 14.756.032.674 & 1.026 .007 & 1,13 \\
\hline & \% Variación & 8,79 & 21,42 & 11,61 & $-2,59$ \\
\hline 2 a 2,5 & 2009 & 17.117 & 10.867.925.640 & 634.920 & 1,23 \\
\hline \multirow[t]{2}{*}{ PM } & 2013 & 18.619 & 13.638 .789 .880 & 732.520 & 1,18 \\
\hline & \% Variación & 8,77 & 25,50 & 15,37 & $-4,07$ \\
\hline 2,5 a 3 & 2009 & 20.838 & 8.672 .650 .572 & 416.194 & 1,32 \\
\hline \multirow[t]{2}{*}{ PM } & 2013 & 22.693 & 10.054.405.966 & 443.062 & 1,27 \\
\hline & \% Variación & 8,90 & 15,93 & 6,46 & $-3,79$ \\
\hline 3 a 3,5 & 2009 & 24.720 & 6.718 .401 .600 & 271.780 & 1,47 \\
\hline \multirow[t]{2}{*}{ PM } & 2013 & 26.873 & 8.258.449.122 & 307.314 & 1,35 \\
\hline & \% Variación & 8,71 & 22,92 & 13,07 & $-8,16$ \\
\hline 3,5 a 4 & 2009 & 28.734 & 5.747 .432 .148 & 200.022 & 1,52 \\
\hline \multirow[t]{2}{*}{ PM } & 2013 & 31.212 & 9.348 .118 .848 & 299.504 & 1,42 \\
\hline & \% Variación & 8,62 & 62,65 & 49,74 & $-6,58$ \\
\hline 4 a 4,5 & 2009 & 33.050 & 9.560 .340 .450 & 289.269 & 1,49 \\
\hline \multirow[t]{2}{*}{ PM } & 2013 & 35.334 & 12.022 .711 .506 & 340.259 & 1,34 \\
\hline & \% Variación & 6,91 & 25,76 & 17,63 & $-10,07$ \\
\hline 5 a 7,5 & 2009 & 45.173 & 3.219 .479 .710 & 71.270 & 2,54 \\
\hline \multirow[t]{2}{*}{$\mathrm{PM}$} & 2013 & 48.696 & 3.462 .334 .296 & 71.101 & 2,37 \\
\hline & \% Variación & 7,80 & 7,54 & $-0,24$ & $-6,69$ \\
\hline 7,5 a 10 & 2009 & 65.150 & 1.031.389.650 & 15.831 & 2,71 \\
\hline \multirow[t]{2}{*}{ PM } & 2013 & 70.335 & 1.037.441.250 & 14.750 & 2,52 \\
\hline & \% Variación & 7,96 & 0,59 & $-6,83$ & $-7,01$ \\
\hline Más de 10 & 2009 & 140.863 & 2.372 .978 .098 & 16.846 & 2,81 \\
\hline \multirow[t]{2}{*}{ PM } & 2013 & 143.422 & 1.878.684.778 & 13.099 & 2,65 \\
\hline & \% Variación & 1,82 & $-20,83$ & $-22,24$ & $-5,69$ \\
\hline
\end{tabular}

Fuente: Elaboración propia a partir de "Mercado de trabajo y pensiones en las fuentes tributarias", Agencia Tributaria. Notas: PM = Pensión Mínima Anual. En 2009 PM = 7651,70 euros anuales; en $2013 \mathrm{PM}=8.300,60$ euros anuales. El incremento de la PM entre ambos años es del 8,5\%. 
Conviene advertir que en los salarios el número de percepciones por persona es relativamente homogéneo y afecta más en todo caso a los tramos de menores salarios, por ser éstos donde hay un número mayor de contratados temporales y a tiempo parcial. Por el contrario, en las pensiones hay una mayor heterogeneidad en el número de percepciones por persona y éste índice tiende a ser mayor cuanto más elevado es el tramo considerado. Dicho de otro modo, los asalariados que tienen un mayor número de percepciones por persona son los que, a pesar de ello, tienen salarios inferiores. Por el contrario, los pensionistas de los tramos superiores son los que suelen tener más de una pensión. Aunque la reducción del número de pensiones por persona es más intensa en dichos tramos, sigue siendo más alto que en los inferiores.

La desigualdad en la distribución de las pensiones es inferior a la existente en los salarios. No obstante, como ya se señalaba para los salarios, lo más relevante es su evolución. En este caso, la desigualdad ha crecido más en las pensiones que en los salarios en el periodo considerado (cuadro 9). Tanto el índice de Theil, como especialmente el índice de Gini, indican que ha habido un incremento significativo de la desigualdad en las retribuciones de los pensionistas.

\section{Cuadro 9. Índices de desigualdad de las pensiones}

\begin{tabular}{lcc}
\hline & & PENSIONES POR TRAMOS DE PENSIÓN \\
\hline \multirow{3}{*}{ GINI } & 2009 & 0,0218 \\
& 2013 & 0,0261 \\
& \% VARIACIÓN & 20,0 \\
\multirow{2}{*}{ THEIL } & 2009 & 0,3464 \\
& 2013 & 0,3593 \\
\hline
\end{tabular}

Fuente: Elaboración propia a partir de los datos de "Mercado de trabajo y pensiones en las fuentes tributarias", Agencia Tributaria (véase cuadro 6)

En cuanto a las prestaciones por desempleo hay un descenso en el total de prestaciones, pues a pesar de que aumenta el número de desempleados se reduce el importe medio anual de la prestación (cuadro 10). En los desempleados, a diferencia de lo que ocurre entre los asalariados ocupados y los pensionistas, al ser únicas las prestaciones por desempleo y pagadas siempre por la misma entidad no cabe la desigualdad. Conviene advertir, que la cifra de desempleados de esta fuente no es equiparable en ningún sentido a la de las demás fuentes que proporcionan datos de desempleo. Por un lado, porque es evidente que no 
todos los que están en paro cobran prestaciones y aquí lo que se consideran son las prestaciones por desempleo. Por otro, porque hay desempleados que sólo lo son una parte del año y las fuentes fiscales consideran a todos los individuos que han pasado por la situación de paro en vez de calcular un promedio anual como ocurre en el caso de la Encuesta de Población Activa, el paro registrado y otras fuentes estadísticas. Es decir, que en las estadísticas derivadas de fuentes fiscales, como ocurre en el caso de los asalariados, un individuo que sólo haya estado parado un mes o un trimestre al año suma uno, mientras que sumaría una porción de desempleado equivalente a un doceavo o un cuarto, respectivamente, en los datos anuales del resto de estadísticas citadas.

Cuadro 10. Prestaciones por desempleo

\begin{tabular}{cccc}
\hline & Desempleados & $\begin{array}{c}\text { Prestación media } \\
\text { anual (euros) }\end{array}$ & $\begin{array}{c}\text { Total prestaciones } \\
\text { (euros) }\end{array}$ \\
\hline 2009 & 5.525 .758 & 4.010 & 22.159 .656 \\
2013 & 5.705 .800 & 3.828 & 21.840 .737 \\
\% VARIACIÓN & 3,3 & $-4,5$ & $-1,4$ \\
\hline
\end{tabular}

Fuente: Elaboración propia a partir de "Mercado de trabajo y pensiones en las fuentes tributarias", Agencia Tributaria.

\section{Cotizaciones a la seguridad social y prestaciones sociales contributivas}

El descenso durante la crisis en el número de ocupados y de asalariados en particular (cuadros 11 y 12) ha supuesto una disminución de los afiliados a la Seguridad Social (cuadro 13). El número de ocupados es una estimación, mientras que el de afiliados es un registro. Con independencia de esa diferencia metodológica, el menor número de afiliados que de ocupados indica que no todos los ocupados están dados de alta en la seguridad social. Resulta llamativo, sin embargo, que la afiliación sea superior en los no asalariados que en los asalariados, superando incluso el cien por cien en algún caso. 


\section{Cuadro 11. Ocupados según Contabilidad Nacional (miles)}

\begin{tabular}{|c|c|c|c|c|c|c|}
\hline & 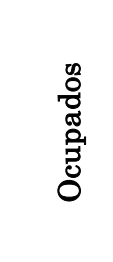 & 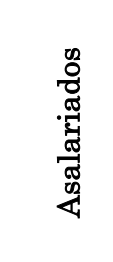 & 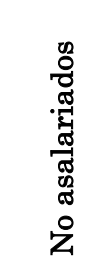 & 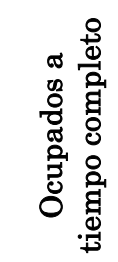 & 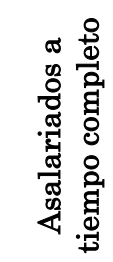 & 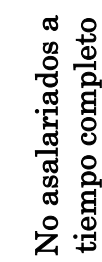 \\
\hline 2009 & 19.987 & 17.318 & 2.669 & 18.642 & 16.132 & 2.510 \\
\hline 2013 & 17.948 & 15.384 & 2.558 & 16.351 & 13.980 & 2.371 \\
\hline \% Evol. & $-10,2$ & $-11,17$ & $-4,16$ & $-12,29$ & $-13,34$ & $-5,54$ \\
\hline
\end{tabular}

Fuente: INE.CNE-2010. Contabilidad Nacional Trimestral

\section{Cuadro 12. Ocupados y parados (miles)}

\begin{tabular}{|c|c|c|c|c|c|c|c|}
\hline & 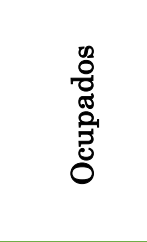 & 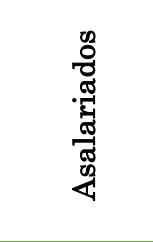 & 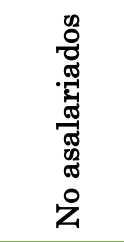 & 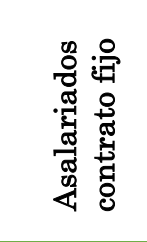 & 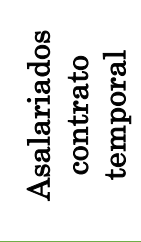 & 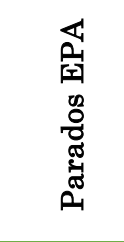 & 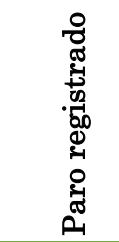 \\
\hline 2009 & $19.106,9$ & $15.881,1$ & $3.225,8$ & $11.877,7$ & $4.003,4$ & $4.153,6$ & 3.644 \\
\hline 2013 & 17.139 & $14.069,2$ & $3.069,8$ & $10.813,6$ & $3.255,5$ & $6.051,1$ & $4.845,3$ \\
\hline \% Evol. & $-10,3$ & $-11,41$ & $-4,84$ & $-8,96$ & $-18,68$ & 45,68 & 32,97 \\
\hline
\end{tabular}

Fuente: Ocupados, asalariados y parados, EPA-INE. Paro registrado, SPEE - SISPE (CNAE-09).

\section{Cuadro 13. Afiliados a la Seguridad Social (miles)}

\begin{tabular}{|c|c|c|c|c|c|c|}
\hline & 苞 & 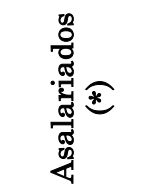 & 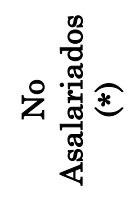 & 卖 & 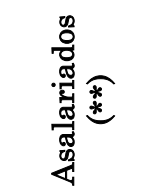 & 乙选急 \\
\hline 2009 & $17.916,8$ & $14.688,5$ & $3.228,3$ & 18.019 & $14.783,7$ & $3.235,4$ \\
\hline 2013 & $16.227,7$ & $13.186,7$ & $3.040,9$ & 16.298 & $13.255,9$ & $3.042,1$ \\
\hline \% Evol. & $-9,43$ & $-10,22$ & $-5,80$ & $-9,55$ & $-10,33$ & $-5,97$ \\
\hline
\end{tabular}

Fuente: Para afiliados MESS (CNAE-09): $(*)$ Serie desestacionalizada por la Subdirección General de Análisis Coyuntural y Previsiones Económicas. Datos del último día de cada mes; $(* *)$ Serie desestacionalizada por el MESS 
Por su parte, el paro crece en mayor proporción que el descenso del empleo, ya que en el periodo considerado se incrementa la tasa de actividad. Es sabido que el paro registrado es inferior al paro de la Encuesta de Población Activa, puesto que no todos los que están en situación en desempleo y buscan activamente trabajo se inscriben en el servicio público de empleo. En cualquier caso, lo significativo es que el paro registrado crece menos que el paro EPA, lo que indica que, a pesar de las dificultades para encontrar empleo, hay cada vez más parados que consideran que el servicio público de empleo no les es de utilidad.

En contraste con el descenso del número de ocupados y afiliados, hay un aumento del número de pensionistas y pensiones (cuadro 14). Sin embargo, el incremento en el número de parados no ha supuesto un aumento paralelo de los beneficiarios del seguro de desempleo. Por el contrario, éstos han caído drásticamente. Si en 2009 los beneficiarios del seguro de desempleo representaban un $45 \%$ de los parados registrados y un $39 \%$ del paro EPA, en 2013 esa cobertura pasa al $27 \%$ y al $21 \%$, respectivamente. Esto explica, entre otras razones, que la pobreza y la desigualdad hayan crecido menos entre los jubilados que entre los parados y ocupados.

\section{Cuadro 14. Beneficiarios de prestaciones económicas contributivas}

\begin{tabular}{cccc}
\hline & Pensionistas & Pensiones & Beneficiarios seguro de desempleo \\
\hline $\mathbf{2 0 0 9}$ & 7.761 .549 & 8.531 .935 & 1.622 .301 \\
$\mathbf{2 0 1 3}$ & 8.243 .054 & 9.065 .830 & 1.289 .192 \\
\% Evolución & 6,20 & 6,26 & $-20,53$ \\
\hline
\end{tabular}

Fuente: Ministerio de Empleo y Seguridad Social

La disminución de afiliados a la seguridad social ha implicado, lógicamente, un descenso del valor de las cotizaciones sociales (cuadro 15). No obstante, ha sido inferior al de afiliados o cotizantes. La cotización media por afiliado ha pasado de ser 5.947,1 euros en 2009 a 6.052 euros en 2013. Este resultado es la consecuencia de factores que actúan en sentidos contrapuestos. La caída de las remuneraciones no supone una reducción proporcional de las cotizaciones ya que éstas dependen de las bases de cotización y éstas se han incrementado. Dichas bases, como es sabido, establecen unos mínimos y máximos para cada uno de los grupos o categorías en que se clasifican las distintas ocupaciones. La mayor 
destrucción de empleo en categorías inferiores implica que las cotizaciones caen menos que el empleo. Por otro lado, sin embargo, el aumento de los salarios más elevados, que se constataba en el apartado anterior, no supone un incremento igual en las cotizaciones si éstos sobrepasan los topes máximos.

\section{Cuadro 15. Cotizaciones a la Seguridad Social y prestaciones sociales contributivas}

\begin{tabular}{cccc}
\hline (Millones de euros) & $\mathbf{2 0 0 9}$ & $\mathbf{2 0 1 3}$ & $\begin{array}{c}\text { \% evolución } \\
\mathbf{2 0 0 9 - 2 0 1 3}\end{array}$ \\
\hline Cotizaciones a la Seguridad Social & $106.552,9$ & $98.210,3$ & $-7,83$ \\
Total prestaciones contributivas & $99.899,7$ & $116.110,9$ & 16,23 \\
Diferencia entre cotizaciones & $6.653,2$ & $-17.900,6$ & - \\
y prestaciones contributivas & & & \\
Pensiones contributivas & $89.972,2$ & $108.579,8$ & 20,68 \\
Pensión media (euros/mes) & 754,06 & 856,37 & 13,57 \\
\hline
\end{tabular}

Fuente: Ministerio de Empleo y Seguridad Social

En contraste con la disminución de las cotizaciones recaudadas, las prestaciones contributivas han aumentado. En este caso, a pesar del mayor número de pensionistas y la moderación en la revalorización de las pensiones, la pensión media ha subido. Es fruto, sobre todo, del acceso de un mayor porcentaje de pensionistas con derecho a pensiones más altas, lo que se conoce como efecto composición. La pensión media anual que era de 11.592 euros en 2009 es de 13.172,3 euros en 2013.

Más allá de lo ya señalado en el apartado anterior, la mejora relativa de las retribuciones de los pensionistas frente a la de los asalariados ocupados y parados, lo que interesa aquí constatar es el paso de un saldo positivo entre cotizaciones y prestaciones, que todavía se mantiene en 2009, a uno fuertemente negativo en 2013. Una de las consecuencias de esta situación es el progresivo recurso al fondo de reserva de la seguridad social para pagar las pensiones. Ya en 2012 se redujo dicho fondo y en 2013 la disminución fue de 9.264 millones de euros.

Con frecuencia se ha planteado la vulnerabilidad del sistema de pensiones, fundamentalmente por motivos demográficos. El envejecimiento de la población supone una variable relevante para analizar la sostenibilidad de las pensiones. Entre 2009 y 2013 la población de 65 o más años ha pasado de ser el 24 por ciento de la población de 16 o más años al 26,3 por ciento; y de representar el 47,6 por ciento de los 
inactivos al 51,1 por ciento. Es decir, no sólo ha aumentado la proporción que representan los mayores de 65 años sino que ha disminuido su tasa de actividad. Dicho de otro modo, hay más población que supera la edad de jubilación, y de esa población hay menos que permanezca en el mercado de trabajo, y entre la que permanece hay una proporción mucho mayor en situación de desempleo. Su tasa de paro se eleva desde el 2,7 por ciento en 2009 al 6,4 por ciento en 2013, a pesar de su menor tasa de actividad.

No es éste, sin embargo, el único, ni probablemente el principal, peligro para el mantenimiento del sistema de pensiones. Es el volumen del empleo y su grado de cualificación lo que tiene una influencia decisiva. Las tendencias demográficas se pueden ver modificadas de forma importante si, como ocurrió en el periodo 1998-2007, vuelve a haber una emigración masiva. Lo que resulta más complicado si no se cambian las características del sistema de crecimiento español es incrementar el empleo y, sobre todo, un empleo de calidad. Si no aumentan más que proporcionalmente las categorías y remuneraciones más elevadas, correspondientes a grupos con bases de cotización y rentas más altas, difícilmente se podrá conseguir que las cotizaciones cubran las prestaciones contributivas.

Con la cotización media por afiliado del año 2013 (6.052 euros), habrían sido necesarios más de tres millones y medio más de afiliados para que las cotizaciones llegasen a cubrir el gasto en prestaciones contributivas $^{4}$. La recuperación del empleo y de la afiliación a la Seguridad Social en el 2014 permite suponer que ha habido un aumento de las cotizaciones sociales y un pequeño freno en las prestaciones contributivas por desempleo, pero eso no logra compensar el incremento en el gasto en pensiones, a pesar de que su revalorización fue menor que en años anteriores.

Algo semejante ocurre con las prestaciones por desempleo, aunque en este caso, paradójicamente, el gasto de la prestación contributiva por desempleo (seguro de desempleo) se ha reducido (cuadro 16), a pesar del aumento en el número de parados. Ha habido una drástica disminución de los desempleados que acceden al seguro de desempleo y ha caído la cuantía media percibida. Se ha producido además un trasvase de las prestaciones contributivas a las asistenciales. De ahí el incremento de los que quedan fuera de las prestaciones contributivas: las pensiones asistenciales; y ante el paro de larga duración una larga lista de prestaciones subsidiarias para los que agotan el seguro de desempleo sin

\footnotetext{
${ }^{4}$ No hemos podido acceder aún a datos definitivos de liquidación del presupuesto de la Seguridad Social para ejercicio del año 2014
} 
encontrar trabajo, como son: el subsidio de desempleo, la Renta Activa de Inserción (RAI), el Programa Temporal de Protección por Desempleo e Inserción (PRODI), el Programa de Recualificación Profesional de las Personas que Agoten su Protección por Desempleo (PREPARA) y el Programa de Activación para el Empleo, para cada uno de los cuáles se exigen determinadas condiciones, entre ellas no sobrepasar un cierto umbral de renta y tener cargas familiares.

\section{Cuadro 16. Prestaciones contributivas por desempleo}

\begin{tabular}{cccc}
\hline & 2009 & 2013 & $\begin{array}{c}\text { \% evolución } \\
\text { 2009-2013 }\end{array}$ \\
\hline Millones de euros & & & $-28,77$ \\
Beneficiarios & $26.803,4$ & $19.091,2$ & $-19,32$ \\
Media anual por beneficiario (euros) & 1.624 .792 & 1.310 .915 & $-11,72$ \\
\hline
\end{tabular}

Fuente: Servicio de Empleo Público Estatal, Estadística de prestaciones por desempleo, Ministerio de Empleo y Seguridad Social

No ha sido posible comparar las prestaciones contributivas por desempleo con la cotización correspondiente a esa contingencia, pues el Ministerio de Empleo y Seguridad Social hace tiempo que no aporta datos al respecto. La gestión del desempleo corresponde al Servicio de Empleo Público Estatal (SEPE), que forma parte de las Administraciones de la Seguridad Social, pero no del Sistema de Seguridad Social (Instituto Nacional de la Seguridad Social, Instituto de Mayores y Servicios Sociales, Instituto Nacional de Gestión Sanitaria, Instituto Social de la Marina, Tesorería General y Mutuas). En consecuencia las cotizaciones por la contingencia de desempleo no están integradas en las cuentas de la Seguridad Social, donde por cierto si se recoge de forma desglosada las aportaciones al sistema de seguridad social que corresponden a las cotizaciones de los que cobran las prestaciones por desempleo.

En todo caso, hay que insistir en que el sistema de carácter contributivo, que se distingue por la obligatoriedad de la inclusión del beneficiario en el sistema de seguridad social (afiliación) y la obligatoriedad de las aportaciones (cotizaciones), tiende a ser insostenible. El gasto en prestaciones contributivas, a pesar de los recortes en las mismas y el desvío hacia las prestaciones de carácter asistencial tiende a superar los ingresos por cotizaciones. Esta es una novedad que trascendiendo a la situación de la crisis que se desata a partir de 2007, tiene que ver con los efectos de los cambios en el mercado de trabajo propiciados por la reforma laboral en curso. 
La reforma laboral de 2012 implica un cambio de largo alcance (Varios autores, 2012). No sólo ha supuesto una nueva vuelta de tuerca en la reducción de costes laborales sino que al debilitar la negociación colectiva de ámbito sectorial a favor de la de empresa, consolida el freno de los salarios en detrimento de la productividad. La reducción de la tasa de cobertura de la negociación colectiva y el estancamiento de la productividad al volver a crecer el empleo apuntan en ese sentido. Si ya antes la negociación colectiva adolecía de contenidos que incentivasen la mejora de la productividad, centrándose sobre todo en el simple reparto del valor añadido, la reforma laboral en curso, al tender a reducir los convenios de carácter sectorial, dificulta la fijación de unas condiciones laborales mínimas comunes para todas las empresas potencialmente competidoras entre sí.

Con ello se afianza el ajuste pasivo de los costes laborales a la productividad en vez de fomentar la competencia mediante la innovación y la mejora de las condiciones de trabajo que estimula el rendimiento de los trabajadores. Se profundiza en un modelo productivo y de crecimiento que ya ha demostrado su insostenibilidad al buscar aumentar la competitividad por la vía de la importación de tecnología sin hacer un esfuerzo paralelo de innovación propia, y del mantenimiento de bajos salarios e inestabilidad en el empleo despreciando la formación y la experiencia y cualificación de los trabajadores. Las empresas que realmente compiten, lo que necesariamente implica en un grado $u$ otro una cierta capacidad de innovación, son todavía muy escasas.

La ruptura de la serie estadística sobre negociación colectiva (Pérez Infante, 2015) impide una comparación sólida, aunque todo parece confirmar la citada reducción de la tasa de cobertura (Cruz Villalón, 2013; Calvo Gallego, 2013, Pérez Infante, 2013). De ahí que el ligero repunte en los salarios fijados en convenios, que el reciente acuerdo entre patronal y sindicatos (III AEC) apuntala, ni siquiera garantice que aumenten significativamente las remuneraciones salariales y las correspondientes cotizaciones. Además de que éstas últimas se ven lastradas por el aumento de las bonificaciones en el pago de las cuotas de la Seguridad Social como forma de abaratar los costes laborales e incrementar a toda costa el empleo a corto plazo, es difícil que no vuelva a producirse una deriva salarial (diferencia entre el salario pactado y el efectivamente percibido) negativa, como ha ocurrido en los últimos años. La más que posible menor cobertura de la negociación colectiva (cuadro 17), a consecuencia de la aplicación de la reforma laboral que ha pretendido minimizar los convenios colectivos sectoriales a favor de los de empresa, así como la precariedad de los nuevos contratos, permite pensar que los incrementos salariales serán muy reducidos si es que no llegan a ser de 
nuevo negativos (cuadro 18).

Es importante tener en cuenta que se trata de salarios nominales, sin deflactar por las variaciones en los precios de consumo, y advertir que los salarios por hora trabajada han aumentado más que los salarios por trabajador, reflejo del mayor porcentaje de los trabajadores a tiempo parcial. El hecho de que el coste ordinario haya crecido más que el total en 2012 y 2014 indica, sobre todo, que en esos años se han reducido más los pagos de vencimiento superior al mes (pagas extraordinarias, pagos por participación en beneficios, primas, objetivos y cualquier otro pago de carácter excepcional) que los que se perciben regularmente cada mes.

\section{Cuadro 17. Convenios y trabajadores afectados por convenios}

\begin{tabular}{ccccccc}
\hline $\begin{array}{c}\text { Año de } \\
\text { efectos } \\
\text { económicos }\end{array}$ & \multicolumn{2}{c}{ Total } & \multicolumn{2}{c}{ Ámbito de empresa } & \multicolumn{2}{c}{$\begin{array}{c}\text { Ámbito superior a la } \\
\text { empresa }\end{array}$} \\
\hline & Convenios & Trabajadores & Convenios & Trabajadores & Convenios & Trabajadores \\
\hline $\mathbf{2 0 0 9}$ & 5.689 & 11.557 .823 & 4.323 & 1.114 .593 & 1.366 & 10.443 .230 \\
$\mathbf{2 0 1 0}$ & 5.067 & 10.794 .334 & 3.802 & 923.222 & 1.265 & 9.871 .112 \\
$\mathbf{2 0 1 1}$ & 4.585 & 10.662 .783 & 3.422 & 928.995 & 1.163 & 9.733 .788 \\
$\mathbf{2 0 1 2}$ & 4.376 & 10.099 .019 & 3.234 & 925.744 & 1.142 & 9.173 .275 \\
$\mathbf{2 0 1 3}$ & 4.367 & 9.762 .303 & 3.252 & 915.299 & 1.115 & 8.847 .004 \\
$\mathbf{2 0 1 4}$ & 2.894 & 6.566 .887 & 2.186 & 554.907 & 708 & 6.011 .980 \\
\hline
\end{tabular}

Fuente: Estadística de Convenios Colectivos de Trabajo, Ministerio de Empleo y Seguridad Social. Datos actualizados a 31 de mayo de 2015. Los datos de 2013 y 2014 son provisionales.

Cuadro 18: Variación de los salarios en \% anual

\begin{tabular}{lcccrcc}
\hline & \multicolumn{2}{c}{$\begin{array}{c}\text { VARIACIÓN } \\
\text { SALARIAL }\end{array}$} & \multicolumn{2}{c}{$\begin{array}{c}\text { COSTE SALARIAL } \\
\text { POR TRABAJADOR Y } \\
\text { MES }\end{array}$} & $\begin{array}{c}\text { COSTE SALARIAL } \\
\text { POR HORA } \\
\text { TRABAJADA }\end{array}$ \\
\hline & PACTADA & REVISADA & TOTAL & ORDINARIO & TOTAL & ORDINARIO \\
\hline $\mathbf{2 0 0 9}$ & 2,25 & 2,24 & 3,20 & 3,20 & 5,35 & 5,30 \\
$\mathbf{2 0 1 0}$ & 1,48 & 2,16 & 0,95 & 0,28 & 1,18 & 0,55 \\
$\mathbf{2 0 1 1}$ & 1,98 & 2,29 & 1,05 & 0,95 & 2,05 & 1,95 \\
$\mathbf{2 0 1 2}$ & 1,00 & 1,16 & $-0,53$ & 0,48 & 0,03 & 1,10 \\
$\mathbf{2 0 1 3}$ & 0,51 & 0,51 & 0,03 & $-0,30$ & 0,38 & 0,05 \\
$\mathbf{2 0 1 4}$ & 0,56 & 0,56 & $-0,13$ & 0,03 & 0,35 & 0,45 \\
\hline
\end{tabular}

Fuente: para la variación salarial: Estadística de Convenios Colectivos de Trabajo, 
Ministerio de Empleo y Seguridad Social. Datos actualizados a 31 de mayo de 2015. Los datos de 2013 y 2014 son provisionales. Para el coste salarial: Encuesta Trimestral de Costes Laborales, INE, elaboración propia como media simple de los cuatro trimestres de cada año

\section{Conclusiones}

Los problemas de competitividad de la economía española, reflejados en una productividad que tiende a crecer menos que en la mayoría de los países europeos, se han tratado de compensar, principalmente, mediante reducciones de los costes laborales. Así se ha hecho tradicionalmente con diversas medidas encaminadas no tanto a moderar directamente los salarios sino a frenar su crecimiento facilitando la contratación temporal. Paralelamente se han ido rebajando costes laborales no salariales como las indemnizaciones por despido y se ha configurado una negociación colectiva donde los aspectos que pueden incidir en mayor medida en la mejora de la productividad a medio y largo plazo, como la formación, la seguridad e higiene en el trabajo y demás aspectos organizativos y de participación, o los referidos a la igualdad de género y la conciliación de la vida laboral y familiar, se han relegado en numerosas ocasiones. La reforma laboral de 2012, aún en curso, no sólo ha intensificado esas tendencias, sino que las ha consolidado al tratar de reducir los convenios colectivos de carácter sectorial en favor de los de empresa, y al aumentar la flexibilidad de contratación y despido, así como la fijación unilateral de las condiciones de trabajo por parte del empresario.

Estamos ante un modelo de crecimiento que se apoya en un círculo vicioso, puesto que la desvalorización de la fuerza de trabajo acaba por reducir su rendimiento. Esto, a su vez, obliga a nuevos frenos al crecimiento de los salarios y demás costes laborales para ajustarlos a los de la productividad. Esta espiral devaluadora ha sido especialmente intensa a raíz de la crisis actual. Antes de que el desplome de la economía se manifestase con claridad, el casi estancamiento de la productividad en la etapa de auge hizo que en algunos años, a pesar de la moderación salarial, los costes laborales creciesen por encima de la productividad, pero en muchos otros años se acompasaron o fueron inferiores a la misma.

Con la crisis, como ya había ocurrido en anteriores recesiones, la rápida e intensa destrucción de empleo, muy superior a la caída del PIB, provoca un súbito aumento de la productividad. No hay, sin embargo, un incremento de los salarios y demás costes laborales paralelo al de la productividad. Esto se justifica por la conveniencia de recuperar beneficios para favorecer la inversión y mejorar el empleo y la competitividad de la 
economía española. Sin embargo, más que en otras ocasiones, la contención salarial vinculada a la precariedad del empleo creado y la persistencia de una tasa de paro muy elevada provocan primero una caída de la demanda interna y más recientemente una recuperación de la misma (consumo e inversión) muy limitada. La inviabilidad de ese modelo de crecimiento se manifiesta, entre otros desajustes, en que las cotizaciones sociales asociadas a una reducida tasa de empleo con bajas remuneraciones no cubren los gastos de las prestaciones sociales de carácter contributivo. En un sistema de reparto como el español esto tiende a generar un desequilibrio insostenible, aunque de momento se haya ido cubriendo con el denominado "fondo de reserva".

Las distintas fuentes estadísticas confirman que ha habido un descenso de las remuneraciones del trabajo, tanto por el bajo nivel de empleo como por su escasa retribución. Esto ha contrastado con un aumento de las prestaciones sociales de carácter contributivo, pensiones y desempleo fundamentalmente. Aunque se ha tratado de frenar estas prestaciones, reduciendo su cobertura, el incremento en el número de pensionistas y la elevada tasa de desempleo han determinado que aumente el desfase entre ingresos por cotizaciones y gastos en prestaciones sociales. La limitada recuperación que se aprecia en los últimos meses apenas logra disminuir el citado desfase. Se está creando un tipo de empleo con remuneraciones muy exiguas para una gran parte de la población, no sólo de los asalariados sino de muchos autónomos. Paralelamente las prestaciones contributivas no dejan de crecer, a pesar de la desaceleración en la revalorización de las pensiones y la reducción de la cobertura del seguro de desempleo. Esto dificulta el acercamiento entre los ingresos y gastos derivados de cotizaciones y prestaciones sociales, respectivamente.

Se ha tratado de afianzar un modelo de crecimiento que ya ha demostrado su inviabilidad para mantenerse a medio y largo plazo. De nuevo se ha dado un paso más, pero de especial relevancia por las características de la reforma laboral en curso, en devaluar costes laborales como forma de crear empleo a corto plazo, en vez de tratar de fomentar la competencia y la mejora de la productividad. No sólo lo demuestra el tipo de contratación, donde predomina una vez más la contratación temporal y a tiempo parcial, y la reducción de salarios. En esta ocasión se están tratando de desmantelar algunos de los principales cauces que podrían contribuir a introducir mayor competencia y aumentar la productividad, como son la negociación colectiva articulada desde los niveles superiores de carácter sectorial hasta los de empresa y/o establecimiento, y una participación más activa de los trabajadores que les implique en mayor medida en la marcha de sus respectivos sectores y empresas. 
Ese modelo de crecimiento ha llevado a una progresiva ampliación de las fluctuaciones cíclicas, especialmente intensas en cuanto al empleo y derivadamente en la productividad. En las fases de expansión se logra recuperar empleo reduciendo costes laborales lo que acaba por paralizar las mejoras de productividad, para recaer así en las recesiones en una brusca destrucción de empleo que recupera momentáneamente la productividad y los beneficios empresariales, para descender de nuevo un escalón más en la degradación de costes laborales. Una serie temporal larga demuestra esta pauta de comportamiento y hace pensar, por tanto, que aunque se logre mantener un cierto tiempo más la creación de empleo, acabe por caer de forma aún más drástica que en ocasiones anteriores (gráfico 3).

\section{Gráfico 3. Empleo (\% crecimiento acumulativo medio del número de ocupados en cada periodo)}

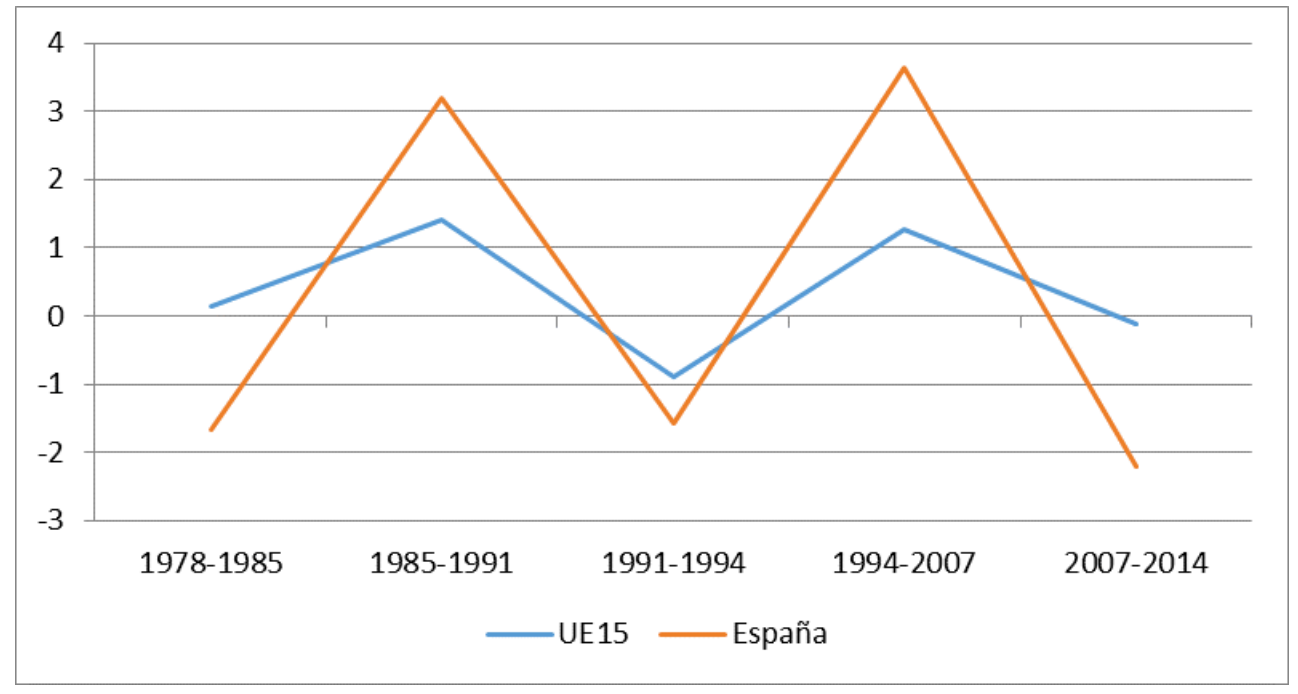

Fuente: elaboración propia a partir de datos de Eurostat (base de datos AMECO)

La desmesurada fluctuación del empleo en España se relaciona con el comportamiento asimétrico de la productividad (gráfico 4). Cuando se crea empleo la productividad tiende a estancarse, mientras que cuando se destruye repunta. Este comportamiento contrasta con el de los países del entorno europeo. En el conjunto europeo el empleo evoluciona de forma más estable, con menores incrementos en las etapas de auge y también 
menores descensos en las recesiones, y la productividad se modifica de forma menos brusca. Incluso en el periodo 1994-2007, en el que el crecimiento de la productividad se enlentece en el ámbito europeo, en España se frena mucho más, acentuándose la diferencia relativa respecto a la Unión Europea.

Cabe esperar, por tanto, que, incluso si prolonga la incipiente recuperación y se sigue creando empleo, cualquier perturbación que suavice el crecimiento tenga como consecuencia una súbita, y probablemente más acusada, destrucción de empleo. No hay nada que indique que el modelo productivo y de crecimiento español está cambiando hacia uno de mayor estabilidad en el empleo con mejoras de productividad. Por el contrario, más que en ocasiones anteriores la recuperación del empleo se basa en un recorte de costes laborales más agudo y con mayores garantías de que se mantenga al haber cercenado la capacidad de presión de buena parte de los trabajadores, tanto por la menor cobertura de la negociación colectiva, especialmente en la pequeña y mediana empresa, como por las mayores prerrogativas con que cuenta el empresario para fijar unilateralmente las condiciones de trabajo. La consecuencia es que la productividad tiende de nuevo a estancarse, aumentando las diferencias de productividad y de salarios entre empresas.

\section{Gráfico 4. Productividad del trabajo (\% crecimiento acumulativo medio del PIB por ocupado en cada periodo)}

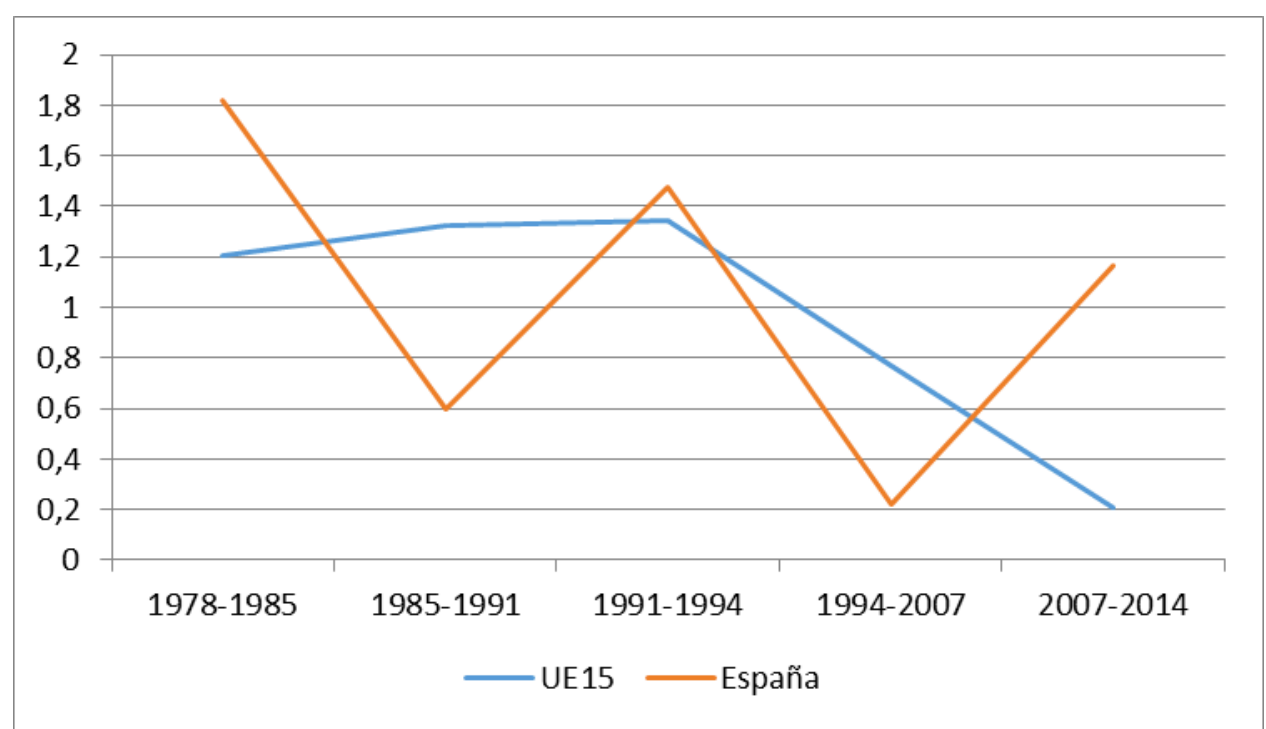

Fuente: elaboración propia a partir de datos de Eurostat (base de datos AMECO) 
Las fuertes desigualdades de productividad entre sectores $\mathrm{y}$ empresas, incluso dentro de un mismo sector, influyen en que se trate de moderar las remuneraciones salariales para adaptarlas a los segmentos de menor productividad. De ahí la dificultad para conseguir un aumento del empleo con suficiente estabilidad y con un grado de retribución suficientemente elevado como para posibilitar que las cotizaciones sociales cubran las prestaciones. El incremento de las desigualdades en las remuneraciones según tramos de los receptores y tamaño de los establecimientos pagadores confirma que se sigue produciendo un proceso de adaptación pasiva a las diferentes circunstancias y niveles de productividad de las empresas. No se propicia una mejora de las condiciones de trabajo y una mayor competencia entre empresas que ayude a elevar la productividad del conjunto del tejido productivo, tarea en la que la negociación colectiva a escala sectorial debe desempeñar un papel decisivo. Por el contrario, se favorece simplemente que las empresas más productivas $\mathrm{y}$, sobre todo, las que más se benefician de la falta de competencia eleven moderadamente las remuneraciones de los trabajadores e incrementen sus beneficios. La reforma laboral, especialmente en lo que se refiere a la negociación colectiva que pretende priorizar los convenios de empresa en detrimento de los convenios sectoriales, no hace sino afianzar el modelo vigente profundizando en la desvalorización de la mayoría de la fuerza de trabajo.

El hecho de que sigan incrementándose las tasas de empleo temporal y en menor medida a tiempo parcial, indica que, a pesar de los intentos de aumentar la contratación indefinida, crecen más los contratos temporales y a tiempo parcial, que los de carácter indefinido y a tiempo completo (cuadro 20). En todo caso, lo más relevante es la duración del contrato de trabajo y el salario-hora, pues cabe aumentar los contratos fijos siempre que se alargue el tiempo en el que se tiene derecho a la indemnización mínima. Esto es lo que está ocurriendo con los denominados contratos de apoyo a los emprendedores y en general con las medidas que han flexibilizado la gestión del contrato indefinido, particularmente en su extinción, aproximándose a lo que plantean los defensores del contrato único. Si el coste laboral es inferior, porque se reduce el salario-hora, se pueden imponer de forma más arbitraria las condiciones de trabajo en el interior de la empresa por parte del empresario y despedir al trabajador es mucho más fácil, poco importa que el contrato sea indefinido.

Por otro lado, el aumento de ocupados con estudios medios tiende a ser superior al de los ocupados con estudios superiores y empiezan a crecer, aunque sea muy moderadamente, los ocupados con estudios bajos que hasta el momento se habían reducido. Un signo más de que la 
contratación tiende a ser de menor calidad. Además, el elevado subempleo de los que tienen estudios superiores, ratificado por la alta tasa de sobrecualificación de dichos titulados en España, apunta a que muchos de los ocupados con estudios superiores desempeñan puestos de trabajo que no se corresponden con su nivel de estudios. En 2014 los ocupados con titulación superior representan alrededor del $42 \%$ del total de ocupados. De los que obtuvieron su titulación en el curso 2019-2010 cuatro años después están en alta en la Seguridad Social un 64,4\%. De los que trabajan por cuenta ajena el $49,3 \%$ tiene un contrato temporal tras esos cuatro años y el $74,2 \%$ trabaja a jornada completa y, un 55,5\% está integrado en un grupo de cotización universitario. Entre estos afiliados por cuenta ajena prácticamente uno de cada cuatro tiene una base de cotización entre 12.000 y 18.000 euros anuales; más de la mitad ocupa un puesto de trabajo cuya base de cotización es inferior a los 24.000 euros; tres de cada cuatro universitarios tienen un empleo con base de cotización inferior a 30.000 euros anuales tres años después de su graduación; y tan sólo algo más del $10 \%$ está en la base de cotización superior a 36.000 euros anuales. En 2014 la base de cotización media de los universitarios afiliados por cuenta ajena fue de 23.735,80 euros anuales, manteniéndose aproximadamente las mismas proporciones en la distribución según bases de cotización ${ }^{5}$.

Todo ello ratifica que con el nivel y calidad del empleo que se está creando difícilmente las cotizaciones a la seguridad social pueden llegar a cubrir las prestaciones contributivas. El modelo de crecimiento está generando desigualdades y desajustes, una de cuyas manifestaciones es el desequilibrio entre ingresos por cotizaciones a la Seguridad Social y gastos en prestaciones sociales contributivas. La incipiente recuperación del empleo desde 2014, que está teniendo continuidad al menos en el primer semestre del 2015, está permitiendo un aumento de los ingresos por cotizaciones sociales y un descenso de los gastos en prestaciones contributivas (cuadros 21 y 22). Sin embargo, se aprecia que el incremento en lo recaudado por cotizaciones es inferior al del empleo y que el descenso en los gastos proviene exclusivamente de las prestaciones por desempleo de carácter contributivo. La tasa de variación de los gastos en pensiones y otras prestaciones contributivas supera con creces a la de las cotizaciones

\footnotetext{
5 Inserción laboral de los egresados universitarios. La perspectiva de la afiliación a la Seguridad Social. Primer Informe, Ministerio de Educación, Cultura y Deporte, Conferencia de Consejos Sociales. (http://www.mecd.gob.es/mecd/dms/mecd/educacionmecd/areas-educacion/universidades/estadisticas-informes/informes/Insercion-laboralegresados-universitarios.pdf)
} 
sociales. Hay que tener en cuenta además, que el margen para recortar gastos en prestaciones contributivas tiende a ser cada vez menor, pues ya se han derivado a prestaciones no contributivas los complementos a mínimos de las pensiones contributivas ${ }^{6}$ y las prestaciones por desempleo suponen un porcentaje pequeño comparado con los demás gastos. El reequilibrio conseguido por el ajuste contable derivado de la exclusión de los complementos a mínimos de las pensiones difícilmente se mantendrá, pues de nuevo en 2015 (enero a abril) el incremento del gasto en prestaciones contributivas está muy por encima del de las cotizaciones.

\section{Cuadro 20. Porcentaje de variación en \% anual}

\begin{tabular}{|c|c|c|c|c|c|}
\hline & & 2014 & IV TR - 2014 & I TR - 2015 & II TR - 2015 \\
\hline \multirow{4}{*}{ Ocupados } & Total & 1,2 & 2,5 & 3,0 & 3,0 \\
\hline & Estudios bajos & $-5,1$ & $-5,3$ & 0,1 & 2,3 \\
\hline & Estudios medios & 1,8 & 3,3 & 5,7 & 4,2 \\
\hline & Estudios altos & 2,5 & 4 & 3,1 & 2,8 \\
\hline \multirow{5}{*}{ Asalariados } & Total & 1,5 & 2,8 & 3,3 & 3,1 \\
\hline & Contrato indefinido & 0,4 & 2 & 2,7 & 1,6 \\
\hline & Contrato temporal & 5,3 & 5,3 & 5,4 & 8,0 \\
\hline & Jornada completa & 1,4 & 2,7 & 2,9 & 3,7 \\
\hline & Jornada Parcial & 2,4 & 3,1 & 3,3 & $-0,9$ \\
\hline No asalariados & & $-0,4$ & 1,5 & 1,4 & 2,4 \\
\hline \multirow{3}{*}{ Tasas } & $\begin{array}{l}\text { Empleo (16 a } 64 \\
\text { años) }\end{array}$ & $+1,2$ & $+1,7$ & $+1,1$ & $+1,9$ \\
\hline & Temporalidad & $+0,9$ & $+0,5$ & $+0,5$ & $+1,1$ \\
\hline & Parcialidad & $+0,2$ & $+0,1$ & $+0,1$ & $-0,6$ \\
\hline
\end{tabular}

Fuente: Elaboración propia a partir de datos de la Encuesta de Población Activa, INE

El freno al gasto en prestaciones contributivas, que a pesar de todo sigue aumentando, se debe, fundamentalmente, a un desplazamiento hacia las prestaciones sociales no contributivas de carácter asistencial. El elevado desempleo y la persistencia en esa situación, así como el creciente número de empleos inestables y con bajos salarios, induce a ese desplazamiento. Por ello se llega a plantear si no será necesario pasar de un Estado de Bienestar centrado en el empleo a otro que garantice unos derechos universales e incondicionales a cada unidad familiar (Rey Pérez, 2015, Varios autores, 2013 y 2015). Esto plantea a su vez cómo garantizar su financiación. Se apunta en ese sentido a reformas fiscales más progresivas que graven proporcionalmente más las rentas superiores y la

\footnotetext{
${ }^{6}$ El descenso en el gasto en pensiones en contributivas en 2014 se debe precisamente a que se desvinculan de dicho gasto los complementos a mínimos en dicho año.
} 
riqueza (herencias y patrimonio). Ahora bien la progresividad tiene unos límites que si no se tienen en cuenta conducen a un callejón sin salida. Gravámenes superiores al 50\% de los ingresos resultan confiscatorios porque pueden desincentivar el rendimiento de los que obtienen rentas del trabajo y el ahorro, que es el origen de las ganancias derivadas de los activos inmobiliarios y financieros.

\section{Cuadro 21. Ingreso por cotizaciones sociales y gasto en prestaciones sociales contributivas}

\begin{tabular}{|c|c|c|c|c|c|}
\hline & & 2013 & 2014 & $\begin{array}{c}\text { Enero-abril- } \\
2014\end{array}$ & $\begin{array}{c}\text { Enero-abril- } \\
2015\end{array}$ \\
\hline \multirow{3}{*}{$\begin{array}{l}\text { Cotizaciones } \\
\text { sociales }\end{array}$} & Millones de euros & $98.210,30$ & $99.155,95$ & $33.153,50$ & $33.552,10$ \\
\hline & $\begin{array}{c}\text { Tasas de variación } \\
\text { anual (\%) }\end{array}$ & $-2,8$ & 0,96 & $-0,2$ & 1,2 \\
\hline & $\begin{array}{c}\text { Cotizantes } \\
\text { (afiliados SS, miles) }\end{array}$ & $16.227,7$ & $16.491,7$ & $16.420,9$ & $16.980,8$ \\
\hline \multirow[t]{2}{*}{$\begin{array}{l}\text { Prestaciones } \\
\text { contributivas }\end{array}$} & Millones de euros & $116.110,9$ & $112.772,3$ & $32.575,7$ & $32.755,9$ \\
\hline & $\begin{array}{c}\text { Tasas de variación } \\
\text { anual (\%) }\end{array}$ & 4,1 & -3 & $-3,2$ & 3,8 \\
\hline \multirow[t]{4}{*}{$\begin{array}{l}\text { Pensiones } \\
\text { contributivas }\end{array}$} & Millones de euros & $108.579,8$ & $104.668,7$ & $29.767,1$ & $30.798,5$ \\
\hline & $\begin{array}{l}\text { Tasas de variación } \\
\text { anual (\%) }\end{array}$ & 4,9 & $-3,6$ & $-3,0$ & 4,1 \\
\hline & $\begin{array}{l}\text { Pensión media } \\
\text { (Euros/mes) }\end{array}$ & 856,37 & 871,01 & 868,47 & 883,89 \\
\hline & $\begin{array}{c}\mathrm{N}^{\circ} \text { de pensiones } \\
\text { (miles) }\end{array}$ & $9.065,83$ & $9.201,08$ & $9.172,03$ & $9.279,34$ \\
\hline
\end{tabular}

Fuente: Ejecución del presupuesto de la Seguridad Social (Tesorería General de la Seguridad Social y Dirección General de Ordenación Económica de la Seguridad Social), Ministerio de Empleo y Seguridad Social.

\section{Cuadro 22. Gasto en prestaciones por desempleo contributivas}

\begin{tabular}{ccccc}
\hline & & $\mathbf{2 0 1 3}$ & $\mathbf{2 0 1 4}$ & Enero-abril-2015 \\
\hline & Miles de euros & $19.091 .157,23$ & $16.462 .188,93$ & $4.702 .641,46$ \\
$\begin{array}{c}\text { Tasas de variación } \\
\text { anual (\%) }\end{array}$ & $-15,6$ & $-13,77$ & $-23,23$ \\
$\begin{array}{c}\text { por } \\
\text { desempleo }\end{array}$ & Beneficiarios & 1.310 .915 & 1.059 .799 & 886.401 \\
& Media (Euros/mes) & 840,1 & 809,5 & 808,2 \\
\hline
\end{tabular}

Fuente: Estadística de prestaciones por desempleo, Subsecretaría de Empleo y Seguridad Social, Secretaría General Técnica, Subdirección General de Estadística, Ministerio de Trabajo y Seguridad Social 
El modelo de crecimiento al poner el énfasis en las reducciones de costes laborales en vez de en aumentos de la productividad, acaba por ser cada vez más insostenible. Es necesario invertir esa espiral devaluadora de la fuerza de trabajo para conseguir aumentos de productividad más efectivos y duraderos. Esto no puede hacerse tratando de actuar exclusivamente sobre el mercado de trabajo, sino que requiere favorecer una mayor competencia en los mercados de bienes y servicios, y cambios en el sistema educativo que ayuden a mejorar la cualificación de la fuerza de trabajo en los niveles requeridos por la demanda de trabajo del sistema productivo.

\section{Bibliografía}

Aragón, J.; Cruces, J.; Duran, A. y Rocha, F (2005): "Las relaciones laborales y la innovación tecnológica en España". Los Libros de la Catarata.

Calvo Gallego, F. J. (2012, a): "Modalidades contractuales, dualidad en el mercado y reformas laborales en el bienio 2010 a 2012 (I)", Documentación laboral, nº 94, págs. 40-83.

Calvo Gallego, F. J. (2012, b): "Modalidades contractuales, dualidad en el mercado y reformas laborales en el bienio 2010 a 2012 (II): la Ley 3/2012”, Documentación laboral, nº 95-96, págs. 127-165.

Calvo Gallego, F. J. (2013): "El impacto de las últimas reformas laborales sobre la estructura de la negociación colectiva”, Temas laborales: Revista andaluza de trabajo y bienestar social, $\mathrm{n}^{\circ}$ 120, (Ejemplar dedicado a: Los efectos de las reformas laborales en la negociación colectiva), págs. 123180 .

Cebrián, I y Moreno, G. (2012): "El debate sobre la temporalidad contractual, la temporalidad empírica y la duración de los contratos" en Gaceta Sindical: Reflexión y Debate. Las políticas de recortes: evaluación de daños, págs. 91 a 112.

Conde Ruiz J. I., Felgueroso F. y García Pérez, J. I. (2010): "Las reformas laborales en España: un modelo agotado" Papeles de Economía Española, n 124,2010 , págs. 128-147. 
Conde Ruiz J. I y González Martínez, C. I. (2013), "Spain 2011 pension reform", Estado del bienestar: sostenibilidad y reformas, 2013; https://editorialexpress.com/cgi-

bin/conference/download.cgi?db_name=xveep\&paper_id=25; También en Documentos de trabajo FEDEA, nº 3, 2012, págs. 1-39.

Consejo Económico y Social (2015): "Memoria sobre la situación Socioeconómica y laboral de España“, año 2014.

Cruz Villalón, J. (2013): "Impacto de las reformas laborales cobre la negociación colectiva”, Temas laborales: Revista andaluza de trabajo y bienestar social, $\mathrm{n}^{\circ}$ 120, (Ejemplar dedicado a: Los efectos de las reformas laborales en la negociación colectiva), págs. 13-32.

Devesa, J. E., Domínguez, I. y Nagore, A. (2013): "La sostenibilidad financiera del sistema de desempleo contributivo en España: análisis comparado 2009-2011", Anales del Instituto de Actuarios Españoles, n ${ }^{\circ} 19$, págs. 155-176.

Fernández Cordón, J. A. (2014): “№ es la demografía, señores pensionistas! ", Anuario de relaciones laborales en España, № . 5, 2014, págs. 215-217.

Fernández Cordón, J. A. y Planelles Romero, J. (2013): "El papel de la demografía en el futuro de la protección social”, Documentación social, $\mathrm{N}^{\mathrm{o}}$ 167, 2013 (Ejemplar dedicado a: Vivir sencillamente para que otros, sencillamente, puedan vivir: Teorías), págs. 153-172.

Galiana, J. M. (2013): “Apuntes sobre la reforma laboral de 2012”, Áreas, n 32 , págs. 29-36.

García, J. I. (2015), "Un balance de los efectos de la reforma laboral de 2012", Cuadernos de Información Económica, n ${ }^{\circ}$ 246, (Ejemplar dedicado a: La reforma laboral de 2012: primer balance), págs. 1-12.

Herce, J. A. (2013): "La reforma de las pensiones en España", Cuadernos de Información económica, $\mathrm{N}^{\mathrm{o}} 235$.

Palacio, J. I. (2013): "Desequilibrio financiero, desajuste laboral: el caso español", Áreas: Revista internacional de ciencias sociales, $\mathrm{n}^{\circ} 32$ (Ejemplar dedicado a: Cambios y reformas laborales en un contexto de crisis), págs. 
75-91.

Palacio, J. I. (2012): "El marco económico de la reforma laboral", Documentación laboral, nº 94, págs. 10-39.

Palacio, J. I. (2011): "Estructura productiva, competencia e innovación", Ciencia e innovación. Reflexiones en un escenario de crisis (Alicia Durán, coord.), Libros de la Catarata, Fundación $1^{\circ}$ de Mayo, Escuela de Organización Industrial, Madrid, 2011, págs. 23 a 72.

Palacio, J. I. y Álvarez, C. (2004): "Mercado de trabajo: análisis y políticas“, Ed. Akal, Madrid, 2004 (capítulo IV, "Determinación de salarios y negociación colectiva”).

Pérez Infante, J. I. (2015): "La negociación colectiva en 2013. Problemática estadística, características y estructura" en UGT Anuario de Relaciones Laborales 2014, págs. 119 a 129.

Pérez Infante, J. I. (2013): "Las reformas de la negociación colectiva desde una perspectiva económica: naturaleza y resultados”, Temas laborales: Revista andaluza de trabajo y bienestar social, $\mathrm{n}^{0}$ 120, (Ejemplar dedicado a: Los efectos de las reformas laborales en la negociación colectiva), págs. 35-83.

Rey Pérez, J. L. y otros (2015): "Sostenibilidad del Estado de Bienestar en España“, Ed. Dykinson.

Toharia, L. (2005): "El problema de la temporalidad en España: un diagnóstico“, Ministerio de Trabajo e Inmigración.

Toharia, L. (2011): "El debate sobre las reformas necesarias para la economía española: el mercado de trabajo" en Gaceta Sindical: Reflexión y Debate. Políticas para una salida social de la crisis, págs. 201 a 236.

Toharia, L., Arranz, J. M., García Serrano, C. y Herranz, V. (2010): "El sistema de protección por desempleo y la salida del paro", Papeles de economía española, $\mathrm{N}^{\mathrm{o}}$ 124, 2010, págs. 230-246.

Varios Autores (2012): "Aspectos clave de la reforma laboral de 2012" (número con distintos artículos), Documentación Laboral, $\mathrm{n}^{\circ}$ 95-96, volúmenes II-III. 
Varios Autores (2013): "Las últimas reformas en Seguridad Social" (número con distintos artículos), Documentación Laboral, $\mathrm{n}^{\circ}$ 99, volumen III.

Varios Autores (2015): "Sostenibilidad financiera y régimen jurídico de la Seguridad Social: un marco de estrategias para las políticas públicas" (número con distintos artículos), Documentación Laboral, $\mathrm{n}^{\circ}$ 103, volumen I. 